\title{
REVIEW ON FABRICATION AND APPLICATION OF REGENERATED BOMBYX MORI SILK FIBROIN MATERIALS
}

\author{
Ke Wang ${ }^{1,2 \dagger}$, Qian Ma ${ }^{1,2 \dagger}$, Hong-Tao Zhou' ${ }^{1}$, Ju-Mei Zhao ${ }^{1}$, Miao Cao ${ }^{3 *}$, Shu-Dong Wang ${ }^{1 *}$ \\ 1 Jiangsu Province Engineering Research Center of Biomass Functional Textile Fiber Development and Application, Department of Textile and Clothing, \\ Yancheng Polytechnic College, Yancheng 224005, China \\ 2 Research Center for Clean Production of Textile Printing and Dyeing (Wuhan Textile University), Ministry of Education, Wuhan 430073, China. \\ 3 Key Laboratory of Yarn Materials Forming and Composite Processing Technology of Zhejiang Province, College of Material and Textile Engineering, Jiax- \\ ing University, Jiaxing 314001, China \\ Corresponding Author. E-mail: Miao Cao (Email: caomia00823@163.com), Shu-Dong Wang (sdwang1983@163.com)
}

'These authors contributed equally to this work

\section{Abstract:}

Natural silk fiber derived from the Bombyx mori (B. mori) silkworm has long been used as a luxury raw material in textile industry because of its shimmering appearance and durability, and as surgical suture for its high strength and flexibility. Regenerated silk fibroin, as the main protein extracted from the cocoons of the B. mori silkworm, recently has gained considerable attention due to its outstanding properties, including facile processability, superior biocompatibility, controllable biodegradation, and versatile functionalization. Tremendous effort has been made to fabricate silk fibroin into various promising materials with controlled structural and functional characteristics for advanced utilities in a multitude of biomedical applications, flexible optics, electronics devices, and filtration systems. Herein, reverse engineered silk fibroin extraction methods are reviewed, recent advances in extraction techniques are discussed. Fabrication methods of silk fibroin materials in various formats are also addressed in detail; in particular, progress in new fabrication technologies is presented. Attractive applications of silk fibroinbased materials are then summarized and highlighted. The challenges faced by current approaches in production of silk fibroin-based materials and future directions acquired for pushing these favorable materials further toward above mentioned applications are further elaborated.

\section{Keywords:}

B. mori silk fibroin; biocompatibility; biodegradation; biomedical application; flexible optics; electronics devices; filtration

\section{Introduction}

In addition to polysaccharides, lignin, natural rubber, and natural polyesters, silk of the proteins class is another kind of abundant naturally derived polymer produced through the secretion "spinning" process by a number of arthropod lineages (Figure 1a). For different sources and biological functions, the silk composition, structure, and properties may differ significantly [1]. Among silk variants, silk derived from the silkworm Bombyx mori (B. mori) is the most popular, characterized, and commercially used silk due to its large-scale availability, reproducibility, and desirable properties (Figure 1b). $B$. mori silk has historically been considered as the queen of textiles because of its unique shimmering appearance, tactile properties, durability, dyeability, excellent mechanical strength, flexibility, breathability, and comfort it provides in warm or cold weather, and it has long been used as a luxury raw material in the textile industry. In addition, it has also been used for surgical sutures since ancient times due to its biocompatibility, biodegradability, and non-immunogenicity. Nowadays, silk sutures are used primarily for eye and lip surgery, intraoral surgery, and some skin wounds, mainly because of their excellent handling and tying capabilities [2, 3].
B. mori silk possesses a core-shell structure comprising a silk fibroin filament core coated with glue-like sericin. Generally, the percentage of silk fibroin protein is about $70-80 \%$, silk sericin accounts around $20 \%-30 \%$, followed by small amounts of other impurities, in one silk thread (Figure 1c) [4]. Silk fibroins are composed of bundles of nanofibrils, which are oriented parallel to the axis of the filaments. The strong interaction between the twisted bundles of nanofibrils is the origin of the excellent mechanical strength of the $B$. mori silk [2,3]. As the major component of $B$. mori silk, the primary structure of silk fibroin consists of $\mathrm{H}$ - $\mathrm{L}$ chain blocks of hydrophobic heavy chains (H-fibroin, approximately $391 \mathrm{kDa}$ ) and hydrophilic light chains (L-chain, approximately $26 \mathrm{kDa}$ ) linked together by disulfide bonds and glycoprotein P25 (approximately $25.2 \mathrm{kDa}$ ) tied to the $\mathrm{H}-\mathrm{L}$ chain blocks through hydrophobic reactions [5]. The silk fibroin primary structure can assume various secondary structural forms, including $\alpha$-helices, random coils, $\beta$-pleated sheets, and $\beta$-turns. The hydrophobic $\mathrm{H}$-fibroin domains form anti-parallel $\beta$-sheet crystalline structures, imparting strength and stiffness, whereas the hydrophilic light chain domains form the less ordered, poorly oriented amorphous matrix adopting random coils, $\beta$-turns, or $\alpha$-helix structures, allowing elasticity (Figure 1d). The abundance of these secondary structures of silk fibroin endows it with a unique hierarchical structure that determines its stability and drives its final properties $[6,7]$. 
a

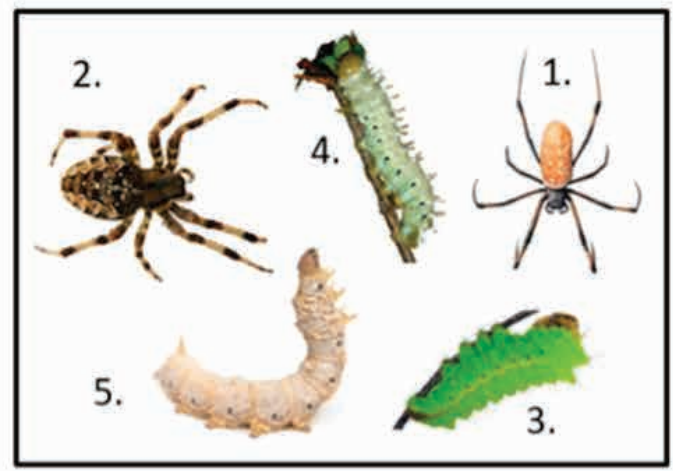

b

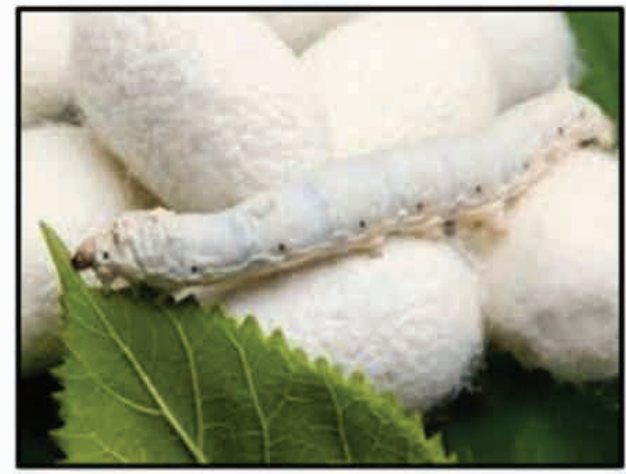

c

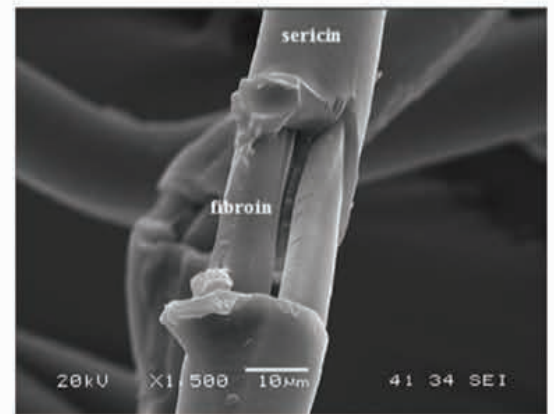

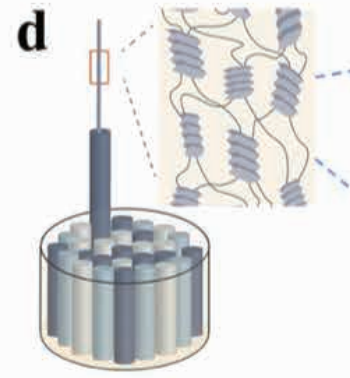

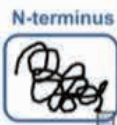

Amorphous

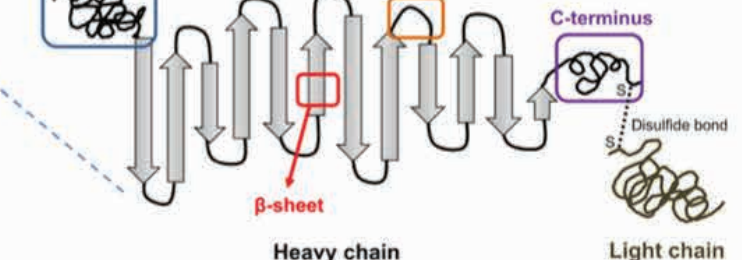

Heavy chain
Light chain

Figure 1. Overview of the origin and structures of silk fibroin. (a) Popular silk sources (1. Nephila clavipes spiders, 2. Araneus diadematus spiders, 3. Antheraea pernyi wildsilk worms, 4. Samia cynthia ricini wildsilk worms, 5. B. mori domestic silkworms). (Reproduced from [2]. CC BY 4.0.). (b) B. mori silkworm and cocoons (Reproduced from [2]. CC BY 4.0.). (c) Composition of B. mori silk (Reproduced with permission [8]. Copyright 2018, The Royal Society of Chemistry). (d) Hierarchical structure of B. mori silk fibroin $[9,10]$ (Reproduced with permission [9]. Copyright 2014, John Wiley and Sons; Reproduced from [10]. CC BY 4.0.).

Conventionally, sericin is removed by a process known as degumming with only silk fibroin left for industrial applications because it has improved mechanical properties, luster, and softhandling than the raw silk [11]. Due to its hierarchical structure and versatility, the utilization of $B$. mori silk fibroin has extended from the textile industry to various high-tech applications in the form of multiple regenerated $B$. mori silk fibroin material formats. Inspired by the ability of $B$. mori silkworms to synthesize and store liquid silk, researchers have attempted to use the topdown approach to reverse $B$. mori silk fibroin filament into solution then to solidify into versatile forms such as fibers, particles, films, hydrogels, and three dimensional (3D) materials for multiple applications such as wearable electronic devices, photonic devices, water ultrafiltration systems, biosensors, drug delivery systems, and tissue engineering [12,13]. The purpose of this review is to provide an overview of recent progress in the development of regenerated $B$. mori silk fibroin materials for diverse applications. Reverse engineered silk fibroin extraction methods are first introduced, and then recent advances in extraction techniques are discussed. Fabrication methods of regenerated silk fibroin materials in various formats are also addressed in detail, and in particular, progress in new fabrication technologies is presented. Attractive applications of either pure or composite regenerated silk fibroin materials are then summarized and highlighted. The challenges faced by current approaches in the production of regenerated silk fibroin materials and future directions acquired for pushing these favorable materials further toward the above-mentioned applications are further elaborated.

\section{Reverse engineered B. mori silk fibroin extraction}

Despite various silk fibroin-based materials regeneration methods, a two-step silk fibroin extraction process including degumming and dissolving is essential.

\subsection{Degumming of raw silk}

Silk degumming is the process by which the gummy layer of sericin, which binds two fibroin filaments, is removed by breaking peptide bonds present between sericin and fibroin through thermochemical treatment of cocoons or raw silk. It has been reported that sericin can cause allergic reactions and infections in humans and inhibit the premature conversion of soluble silk (silk I) into gelated and $\beta$-sheet silk conformations [14]. Therefore, it is necessary to eliminate sericin and other impurities for better utilization of the silk. Conventional degumming is based on using boiling water or aqueous solutions containing soap, alkaline, acid, enzyme, or amine to hydrolyze the sericin (Figure 2) [15]. Comparative analysis of various degumming methods is provided in Table 1.

Water degumming is a green processing method and the cheapest one involving no use of chemicals. However, high temperature, long and repeated processing times, and pressure are always required for efficient removal of sericin. Besides, it is reported that water degumming has the possibility of causing silk fibroin damage at such high temperature for long time, and the problem of incomplete degumming. Thus, this process is not commercially adopted. Water degumming 


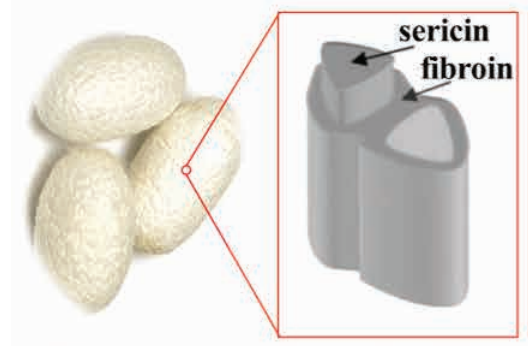

Silk Cocoon Raw Silk Fiber

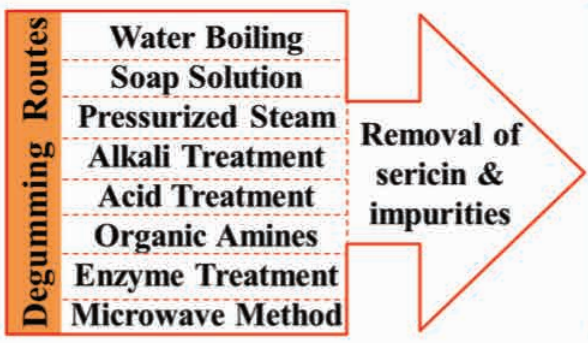

Silk Fibroin

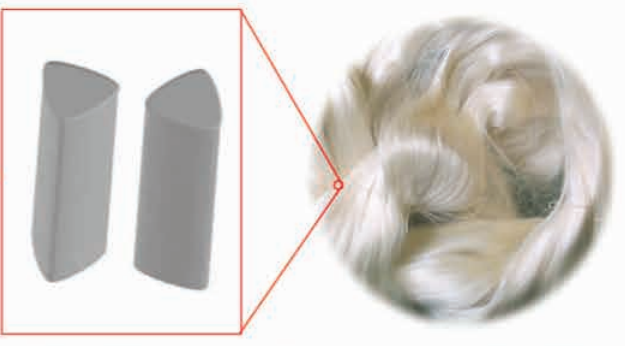

Degummed Silk Fibers

Figure 2. Degumming routes of silk fibers.

is commonly used to soften and partially dissolve sericin by soaking cocoons into water with a temperature of $50-60^{\circ} \mathrm{C}$ to enable the silk filament unwinding in silk reeling in the textile industry [16].

Soap degumming involving treating silk with a slightly alkaline soap solution is one of the most commonly used method. Various sodium-based soap, such as sodium stearate, sodium myristate, sodium laurate, sodium arachidate, sodium oleate, sodium ricinoleate, and sodium caprylate, based on distinct oils such as olive oil, palm oil, coconut oil, laurel oil, canola oil, palm kernel oil, and tallow oil have been employed for soap degumming purposes. The removal of sericin by soap solutions is due to alkali formation upon soap hydrolysis, which forms chemical bonds with sericin and turns it into soluble soda salt. Therefore, soaps with greater hydrolysis capacity perform more effective degumming. The degumming effect of soapbased treatment is also influenced by parameters such as temperature, degumming time, liquor ratio, and $\mathrm{pH}$ of solution. Generally, the quantity of soap, degumming temperature, degumming time, liquor ratio, and $\mathrm{pH}$ required with the soap solution may approximately take the values of $20 \%-30 \%$ soap to the weight of material, $90-95^{\circ} \mathrm{C}, 1.5-2 \mathrm{~h}, 30-40: 1,9.7-$ 10.5 , respectively. Though the soap degumming method has advantages of mild processing, avoidance of over-degumming, and increasing the softness, whiteness, absorbency, and luster properties of the resultant fibroin fibers, the load of soap in the solution is high, and it is susceptible to hard water. In order to avoid metallic complex deposits and resulting stains, the water should be properly softened [17-19].

Alkali degumming is another most commonly used method both in industry and laboratory since it's beneficial both on economic and quality grounds. Various alkalis, including sodium carbonate $\left(\mathrm{Na}_{2} \mathrm{CO}_{3}\right)$, sodium bicarbonate $\left(\mathrm{NaHCO}_{3}\right)$, sodium hydroxide $(\mathrm{NaOH})$, potassium carbonate $\left(\mathrm{KCO}_{3}\right)$, sodium silicate $\left(\mathrm{Na}_{2 x} \mathrm{SiO}_{2 y+x}\right)$, sodium pyrophosphate $\left(\mathrm{Na}_{4} \mathrm{P}_{2} \mathrm{O}_{7}\right)$, trisodium phosphate $\left(\mathrm{Na}_{3} \mathrm{PO}_{4}\right)$, borax $\left(\mathrm{Na}_{2}\left[\mathrm{~B}_{4} \mathrm{O}_{5}(\mathrm{OH})_{4}\right] \cdot 8 \mathrm{H}_{2} \mathrm{O}\right)$, and ammonia $\left(\mathrm{NH}_{3}\right)$, have been investigated for use as degumming agents. Desired $\mathrm{pH}$ and appropriate concentration of the alkali solution is important for achieving high degumming efficiency and not causing injury to the silk fibroin. However, alkalis are always used in combination with soap or detergents, because it leaves the resultant fibers a dirty yellowish color and harsh appearance when used alone for degumming [20, 21].
Degumming of silk using dilute acid, such as tartaric acid, lactic acid, oxalic acid, citric acid, succinic acid, malonic acid, trichloroacetic acid, monochloroacetic acid, glacial acetic acid, and sulfuric acid, is an approach that has long been practiced. Effective acid degumming occurs in the $\mathrm{pH}$ range of 1.5-2. These dilute acids specifically perform a hydrolytic attack on sericin protein to break peptide bonds between aspartic acid and glutamic acid. Acid degumming provides very fast degumming rate and avoids the use of high temperature. However acid degumming is used less due to the fact that alkaline solution is safer for fibroin than acids [22, 23].

Degumming of silk by enzymes such as trypsin, papain, and bacterial enzymes is also a method that has long been practiced. The mechanism of enzymatic degumming is that the proteolytic enzymes cleave the peptide and amide linkages of sericin and convert them into amino acid. Different enzymes show effective degumming at different $\mathrm{pH}$. Compare this with nonspecific hydrolytic reactions of other methods: studies have indicated that proteolytic enzymes react only at specific sites. Since degumming by this method is generally carried out at comparatively low temperatures ranging from $37^{\circ} \mathrm{C}$ to $60^{\circ} \mathrm{C}$ under mildly alkaline or acid conditions, enzymatically degummed silk fibers are less damaged with a higher degree of surface whiteness and soft handle compared with soap- or alkali-treated silk fibers. The disadvantage of this method is that hydrophobic impurities such as natural wax, twisting oil, and sericin cannot be completely removed due to the mild processing conditions. Moreover, it is unsuitable for large-scale use due to its low efficiency [24, 25].

Organic amines such as methylamine, ethylamine, diethylamine, and triethylamine have also been investigated as alternatives degumming agents to optimize the degumming conditions. The mechanism of amine degumming is similar to that of alkalis, since sericin removal from silk fibers by this method is associated with the fact that amines ionize in water to give hydroxyl $(\mathrm{OH})$ ions. Reports have shown that under optimized conditions amine degumming shows a degumming effect comparable with Marseilles soap degumming but that was less susceptible to the hardness of water. The disadvantage of this method is that gradual removal of sericin leads to a low degumming rate $[26,27]$.

Until now, water treatment has been used to soften and partially dissolve sericin to enable the silk filament unwinding in silk reeling in textile industry. $\mathrm{Na}_{2} \mathrm{CO}_{3}$ is the most highly preferred 


\begin{tabular}{|c|c|c|c|c|c|c|}
\hline 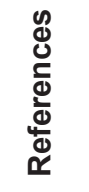 & $\stackrel{\varphi}{\circ}$ & $\underset{\frac{\sigma}{1}}{\stackrel{2}{\leftarrow}}$ & $\begin{array}{l}\bar{N} \\
\stackrel{\sim}{ }\end{array}$ & $\begin{array}{l}\text { N } \\
\mathbb{N}\end{array}$ & $\begin{array}{l}\stackrel{\sim}{N} \\
\stackrel{\mathbb{N}}{N}\end{array}$ & $\begin{array}{l}\hat{N} \\
\hat{N}^{-}\end{array}$ \\
\hline 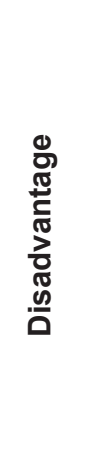 & 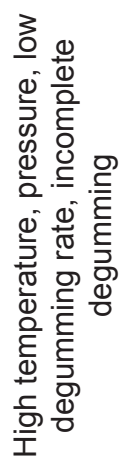 & 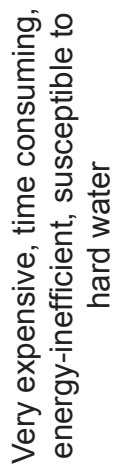 & 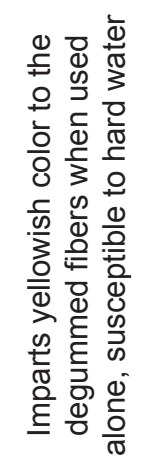 & 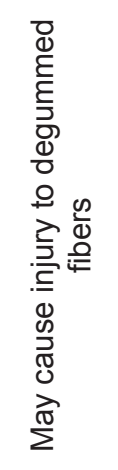 & 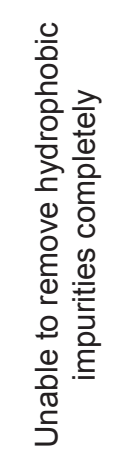 & 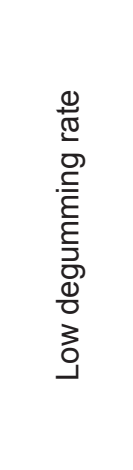 \\
\hline 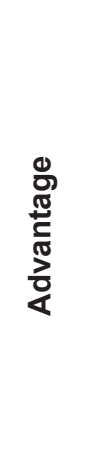 & 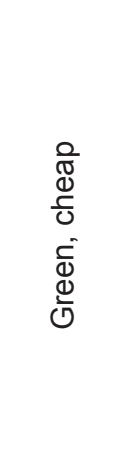 & 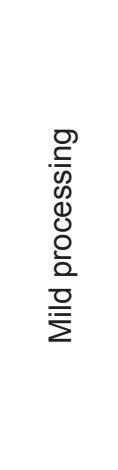 & 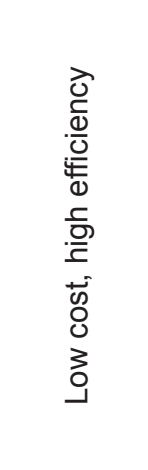 & 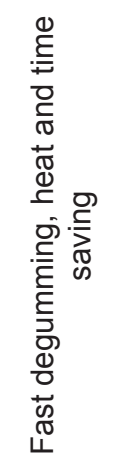 & 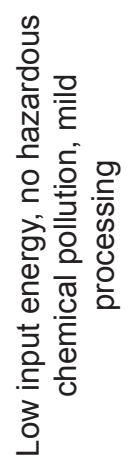 & 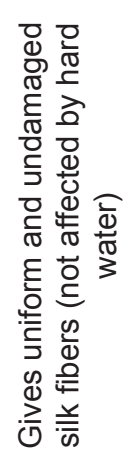 \\
\hline 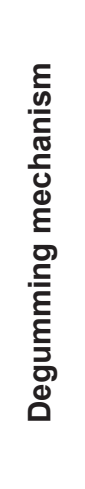 & 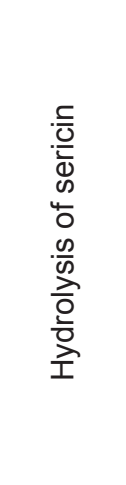 & 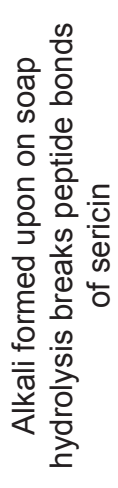 & 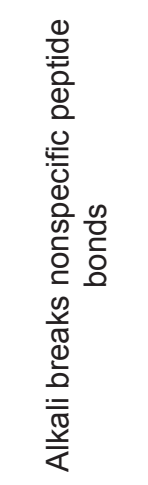 & 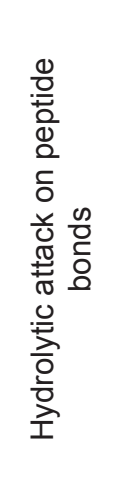 & 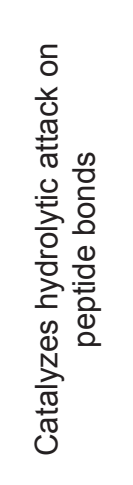 & 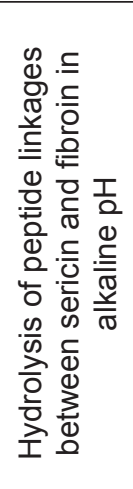 \\
\hline 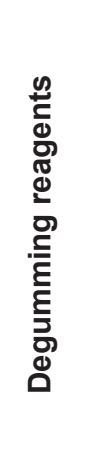 & $\frac{\substack{\bar{d} \\
\frac{\pi}{3}}}{3}$ & 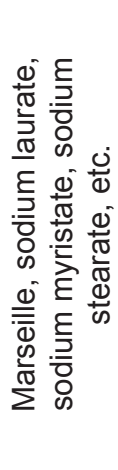 & 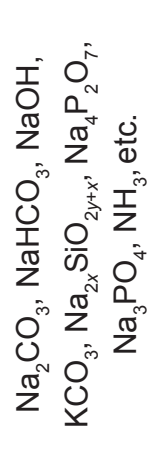 & 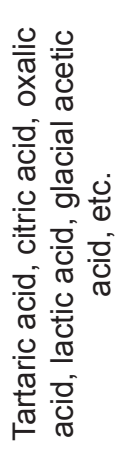 & 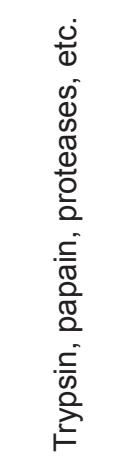 & 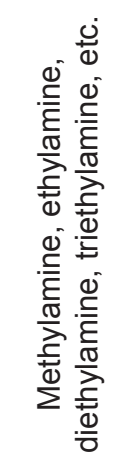 \\
\hline 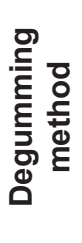 & 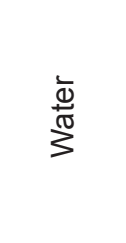 & க) & 崖 & $\overline{\mathrm{Q}}$ & $\begin{array}{l}\stackrel{\oplus}{N} \\
\underset{w}{N}\end{array}$ & 产 \\
\hline
\end{tabular}


and the most common agent adopted in laboratory processes $[11,28]$. Soda made from $\mathrm{Na}_{2} \mathrm{CO}_{3} / \mathrm{NaHCO}_{3}$ is the most widely used alkali to be mixed with soap or detergents for degumming in industry $[29,30]$. The degumming waste solution using this method not only contains a large quantity of sericin, but also includes chemicals of alkalis, soap, and so on. Thus, concerns for environmental protection and sustainability of resources have prompted researchers to explore green, clean, and facile degumming methods to obtain uniform, undamaged degummed silk fibers with improved properties. Research with different focuses can mainly be divided into three categories, using new greener degumming agents, using new energy, and improving the conventional degumming methods in a green way. For example, Wang et al. synthesized a biodegradable amino acid-type anionic surfactant with amino acids of silk fibroin and lauroyl chloride for silk degumming. They studied it systematically in comparison with the traditional degumming methods such as $\mathrm{Na}_{2} \mathrm{CO}_{3}$ and neutral soap. The experimental results showed that the degumming effect of the developed new silk protein surfactant was comparable to neutral soap and far superior to $\mathrm{Na}_{2} \mathrm{CO}_{3}$, and the degumming waste liquid is easily decomposed by microbials [31]. Other greener degumming reagents such as $\mathrm{Ca}(\mathrm{OH})_{2}$ [32], halotolerant metalloprotease isolated from metabolites of Vibrio sp. LA-05 [33], an enzyme from natural sources such as papaya skin, pineapple skin and guava leaf [34], protease from Bacillus sp. C4 [35], hydrated lime water [36], and alkyl polyglycoside [37] have been explored for treatment. Microwave-assisted silk degumming was carried out by Haggag et al. [38] and Mahmoodi et al [39]. Gupta et al. employed infrared heating as an approach for sericin removal and compared the result with that of the conventional high temperature high pressure (HTHP) process. Their results showed that complete removal of sericin could be achieved by using a lower temperature, lower time of treatment and lesser water consumption as compared with the HTHP process [40]. Vyas et al. [41] and Cai et al. [42] performed ultrasonicationassisted silk degumming treatment in the presence of different degumming agents. This method has the advantages of short processing time and uniform degummed silk fibers. Lo et al. tried a recyclable, lower water consumption, and lower energy consumption method to degum silk by using $\mathrm{CO}_{2}$ supercritical fluid under acidic condition. Their results showed that the quality of silk fibroin degummed by $\mathrm{CO}_{2}$ supercritical fluid was found to be better when compared with the silk degummed by $\mathrm{NH}_{4} \mathrm{OH}$. The $\mathrm{CO}_{2}$ emission can be removed and reused for the next degumming procedure [43]. Cao et al. synthesized strongly alkaline electrolyzed water (SAEW) with a $\mathrm{pH}$ of 11.5 as a degumming agent by electrolyzing tap water with a laboratory-made combined water electrolyzer. The hardness of SAEW was found to be $30 \%$ less than that of the tap water, whereas the concentrations of $\mathrm{Na}^{+}$in SAEW were $18 \%$ higher than those in the tap water. Their results showed that there was no evident difference among the surface properties of silk fibroin degummed by SAEW, $\mathrm{Na}_{2} \mathrm{CO}_{3}$ and neutral soap degumming methods (Figure 3) [44]. Wang et al. performed pressurized steam treatment on raw silk to remove sericin. It was found that steam treatment with lower pressure $(0.14$ $\mathrm{MPa}$ ) and long residence time (90 min) generates no adverse effects on the physicochemical properties of the degummed silk fibers [45].

\subsection{Dissolving of degummed silk}

Dissolving of the degummed silk is the next step followed by degumming of silk. Either aqueous or nonaqueous silk fibroin solution can be obtained from which a range of silk fibroinbased materials in versatile formats can be fabricated [46, 47]. Table 2 provides commonly used methods for dissolving degummed silk.

An aqueous silk fibroin solution is the most commonly utilized reverse engineered silk fibroin solution for generation of many different silk fibroin formats [46]. The common strategy for the preparation of aqueous silk fibroin solution is the dissolution of degummed silk in inorganic salt systems. Among all solvents, the two most widely used solvent systems for dissolving include the highly concentrated aqueous $\mathrm{LiBr}$ solution and the ternary solvent system based on $\mathrm{CaCl}_{2} / \mathrm{CH}_{3} \mathrm{CH}_{2} \mathrm{OH} / \mathrm{H}_{2} \mathrm{O}$ with $1 / 8 / 2$ molar ratio. Other inorganic salt systems including $\mathrm{Ca}\left(\mathrm{NO}_{3}\right)_{2} /$ $\mathrm{CH}_{3} \mathrm{OH}$, LiSCN, NaSCN, and $\mathrm{ZnCl}_{2}$ are also employed [47, 48]. The dissolving of silk fibroin in inorganic salt systems is due to hydrogen bond disruption in the crystalline structure (ordered, hydrophobic, and high-density $\beta$ sheet region). It is worth noting that the dissolved silk fibroin salt solution requires extensive dialysis and concentration before the regenerated silk fibroin is suitable for use. The concentration process is normally done by dialysis against an aqueous polyethylene glycol solution (20 wt\%) to extract water [15, 46, 47]. Sometimes freezedrying followed by redissolving at required concentration is needed. Thus, the whole dissolving, dialysis, concentration, and freeze-drying processes for extraction of regenerated silk fibroin are time-consuming [4]. In addition, the regenerated silk

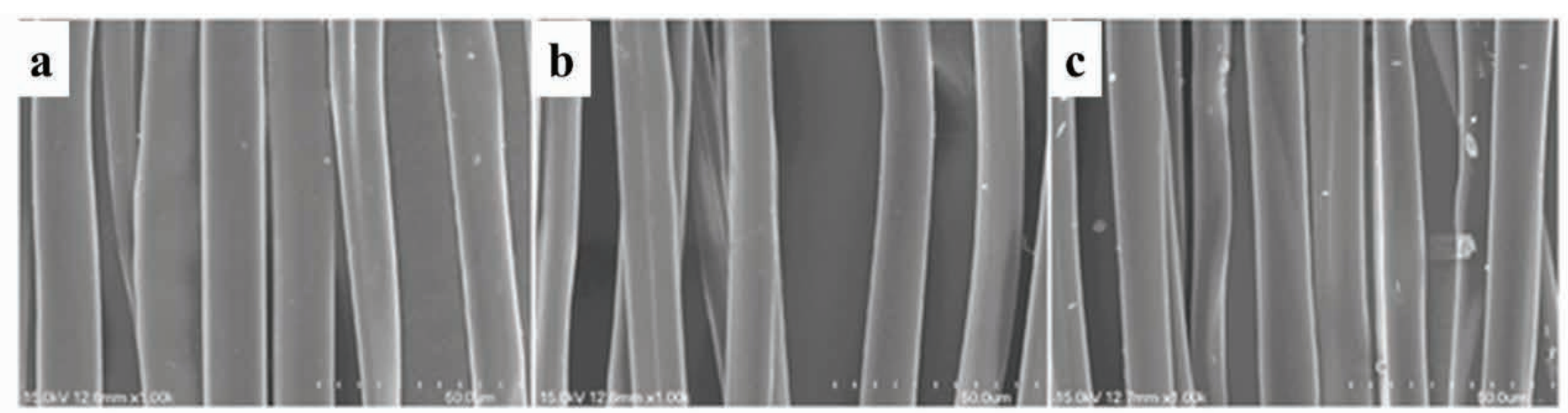

Figure 3. Surface images of single filament of silk fibroin degummed from different degumming methods. (a) Neutral soap, (b) $\mathrm{SAEW}$, (c) $\mathrm{Na}_{2} \mathrm{CO}_{3}$. (Reproduced from [44]. CC BY 3.0.). 


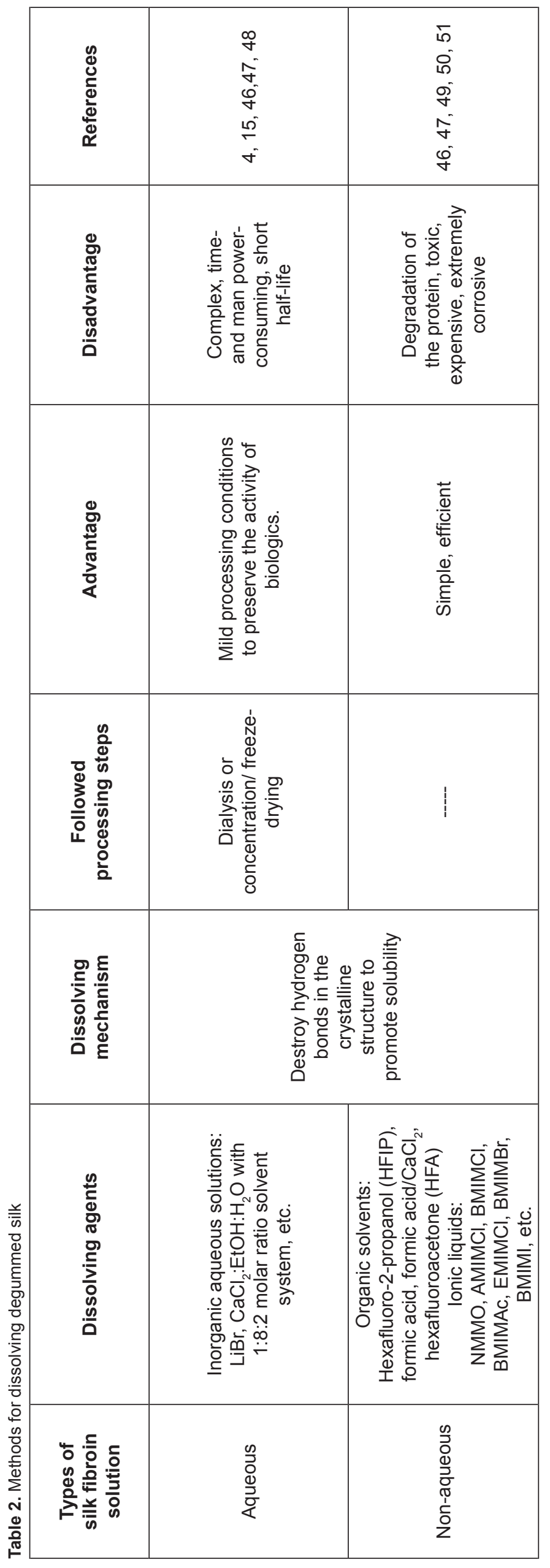

fibroin solution is very unstable and easily denatured and can aggregate to a gel state very easily $[46,47]$.

Nonaqueous silk fibroin solution primarily used for producing regenerated fibers and films via wet spinning, dry spinning, and electrospinning. The most commonly used solvents for artificial spinning are hexafluoro-2-propanol (HFIP), hexafluoroacetone (HFA), formic acid, and formic acid/ $\mathrm{CaCl}_{2}[47,49,50]$. These solvents first cause decomposition of the hydrogen bonds and then break down the peptide bonds. However, these solvents are strongly corrosive, toxic, and volatile. And the obtained silk fibroin solution is not conducive to preservation. Ecofriendly solvents such as $\mathrm{N}$-Methylmorpholine $\mathrm{N}$-oxide (NMMO) and ionic liquids such as 1-Allyl-3-methylimidazolium chloride (AMIMCI), 1-Butyl-3-methylimidazolium chloride (BMIMCl), 1-Butyl-3-methylimidazole acetate (BMIMAc), 1-Ethyl-3-methylimidazolium chloride (EMIMCI), 1-Butyl3-methylimidazolium bromide (BMIMBr), 1-Butyl-3methylimidazolium iodide (BMIMI), etc. have also been explored for dissolving. Compared with the organic solvents or inorganic salt solvents, dissolution in ionic liquids has the advantages of simple, rapid, and greener preparation processes; stable solutions; elimination of the use of toxic organic volatile liquids; and convenient recycling. However, dissolution in ionic liquid needs high temperatures, which can lead to the degradation of silk protein $[46,47,50,51]$.

Recently, Wang et al. proposed a green and environmentfriendly method to enhance efficiency of aqueous silk fibroin solution preparation. In particular, they used excess acetone to extract concentrated silk fibroin-LiBr solution for dialysis. The required dialysis time can be reduced by half using this method. It was found that the stability, peptide chains, and secondary structure of regenerated silk fibroin are minimally changed. In addition, the resulting acetone and salt in wastewater can be easily separated and recycled for silk fibroin regeneration [52]. Yet, it can be seen that the extraction of regenerated silk fibroin with only mild degradation and stable $\beta$-sheet conformation in large scale by cost effective and easy methods is still a problem.

\section{B. mori silk fibroin materials fabrication}

After researchers successfully obtain the silk solution, the regeneration of silk fibroin into novel material formats such as fibers, particles, films, hydrogels, and $3 \mathrm{D}$ materials with different morphologies can be done, according to the type of end-application (Figure 4).

In comparison with natural silk fiber, regenerated silk fibers can be prepared by wet spinning, dry spinning, and electrospinning. Generally, silk fibroin solution used for artificial spinning is primarily nonaqueous silk fibroin dissolved with organic solvents or ionic liquids because of the better rheological properties of the solution and better evaporation of the solvent $[46,47]$. In wet spinning, the silk protein solution is extruded through a spinneret directly into a coagulation bath that initiates solidification into fibers via precipitation. In contrast, dry spinning solidification of the fiber occurs due to the evaporation of a volatile solvent [59]. Electrospinning is a simple and 

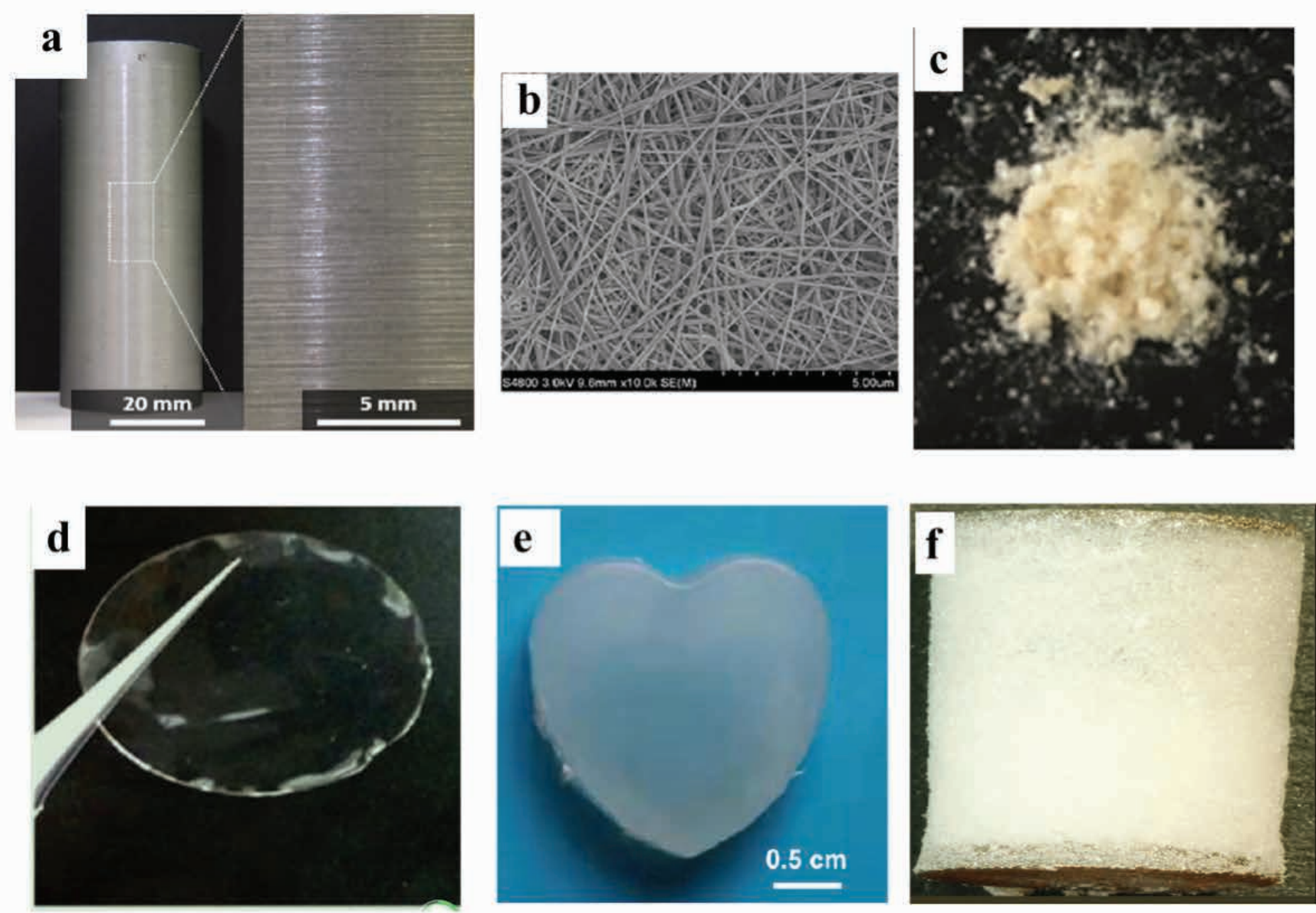

Figure 4. Basic structures of silk fibroin-based materials include (a) regenerated silk fibroin fiber by wet spinning (Reproduced from [53]. CC BY 4.0.), (b) silk fibroin nanofibers by electrospinning (Reproduced from [54]. CC BY 4.0.), (c) silk fibrin nanoparticles (Reproduced with permission [55]. Copyright 2020, John Wiley and Sons), (d) silk fibroin film (Reproduced from [56]. CC BY 4.0.), (e) silk fibroin hydrogel (Reproduced from [57]. CC BY 4.0.), and (f) silk fibroin 3D sponge (Reproduced from [58]. CC BY 3.0.).

useful technique for producing nano/micro fibers possessing large surface areas. By these artificial spinning processes, the diameter, morphology, and mechanical properties of the regenerated silk fibroin fibers obtained can be conveniently modified. Moreover, the regenerated silk fibroin fibers can be endowed with diverse optical, electrical, and biofunctional properties by the addition of various functional fillers during fabrication [60]. For example, Ma et al. fabricated photochromic regenerated silk fibroin/Tungsten trioxide nanoparticles hybrid fibers via wet spinning process [60]. Mohsen et al. fabricated short staple microfibers based on chitosan or silk fibroin via the wet spinning technique to adsorb hexavalent chromium from aqueous solution [61]. Mostafavi et al. fabricated vitamin D-loaded silk fibroin/polycaprolactone (SF/PCL) nanofibrous scaffolds for bone tissue engineering applications [62]. Besides these conventional processes, straining flow spinning recently appears as a versatile and robust technique that allows efficient spinning of regenerated silk fibers. Geometrical and hydrodynamic processing parameters can be integrated into this technique, which allows spinning under a much wider range of chemistries [63]. Liquid exfoliation, which directly exfoliates silk nanofibrils from degummed silk fibers, is another newly developed method that can preserve the native structural elements and features of silk fibers with the aim to rearrange them at the nanofibril level for enhanced properties [64, 65].
Silk fibroin particles can be fabricated by either the top-down method or the bottom-up method. The top-down method involves simply chopping, grinding, and crushing the SF degummed fibers into smaller aggregates. This method generally results in big nanoparticle aggregates with a wide size range and needs a long time and specific apparatus [8, 46]. The bottom-up method uses the silk fibroin solution as the starting material. Broad bottom up-methods such as selfassembly, freeze-drying, and grinding, freeze-thawing, spraydrying, jet-breaking, electro-spraying, microfluidic technique, dissolution, and salting out are applied to produce silk fibroin particles $[8,66]$. The self-assembly method takes advantage of silk fibroin self-assembly behavior ruled by hydrophilic and hydrophobic chain interactions. For example, Xiao et al. fabricated regenerated silk fibroin microsphere-embedded $\mathrm{Fe}_{3} \mathrm{O}_{4}$ magnetic nanoparticles for immobilization of zymolyase through a controllable ethanol-induced interface self-assembly. The prepared microsphere exhibited high immobilization efficiency [67]. Spray-drying, jet-breaking, and electro-spraying are similar technologies, which involve the breaking down of the aqueous silk fibroin flow into small droplets by force $[8,68]$. Dissolution represents the most common method for obtaining silk fibroin particles. It is based on the reduction of the silk fibroin chain solubility in the presence of organic solvents such as acetone, ethanol, dimethyl sulfoxide (DMSO), and methanol, leading to phase separation $[69,70]$. Salting out is another approach employed for the production of silk fibroin 
particles. The formation of particles results from the increased hydrophobic interaction between the SF protein chains due to the dehydration effect of the added salt ions. The manipulation of the solution $\mathrm{pH}$ has been found to have a profound effect on the silk secondary structure, zeta potential, as well as salting out efficiency [59].

Silk fibroin films can be easily prepared by solution casting, spin-coating, or layer-by-layer deposition methods [2, 14]. Water insoluble and flexible silk fibroin films can be fabricated by adjustment of $\beta$-sheet content in the films via controlled drying, water annealing, stretching, and organic solvents treatment [56, 62]. Wang et al. fabricated silk fibroin films with tunable ductility and porosity by adjusting the protein self-assembly process through combinations with glycerol and polyethylene glycol 400 and regulating the film-casting temperature. Among various conditions screened, the composite film with a mass ratio of silk fibroin/polyethylene glycol 400/glycerol of 10:5:3 prepared at $4^{\circ} \mathrm{C}$ exhibited remarkable ductility with a tensile strength of $2.7 \pm 0.2 \mathrm{MPa}$ and an elongation at the break of $164.24 \pm 24.20 \%$ [71]. Silk films with micro/nano-scale patterned morphology can be prepared by the nanolithography technology including soft-lithography, photolithography, ion beam lithography, and nanoimprinting. Micro/nano-scale patterned silk fibroin films have the potential being explored for guided cell growth and as optical storage medium [72, 73]. Softlithography involves casting the aqueous silk fibroin solution on nanostructured surfaces made from elastomeric molds such as polydimethylsiloxane (PDMS) [74]. Ion beam lithography uses an accelerated beam of ions to create nanostructures on cure silk fibroin films [75]. Photolithography is an efficient and costeffective technique that uses light to define patterns on cure silk fibroin films [76].

Silk fibroin hydrogels can be prepared through sol-gel transition of fibroin aqueous solution triggered by physical or chemical processes, where a molecular network forms by controlling the formation of $\beta$-sheet structures as crosslinks for silk $[14,59]$. Physically crosslinked silk fibroin hydrogels can be produced by temperature control, application of shear force, ultrasonication, and electrical current, etc. The underlying mechanism of this process is the self-assembly of proteins via enhanced hydrophobic interactions. Chemically crosslinked silk fibroin hydrogels can be produced by $\mathrm{pH}$ control; addition of precipitating agents such as concentrated salt solutions, organic solvents, surface agents, large polymeric precipitating agents, and small neutral additives; chemical stabilization; and chemical modification. Generally, a lower $\mathrm{pH}$ and a higher incubation temperature facilitate increased kinetics toward the sol-gel transition [77, 78]. In addition to the above-mentioned methods, Hasturk et al. recently fabricated silk-gelatin hydrogel scaffold with tunable gelation kinetics, mechanical properties and bioactivity for cell culture and encapsulation via enzymatic crosslinking [79]. Marín et al. synthesized composite hydrogel of regenerated silk fibroin incorporating gold nanoparticles (AuNPs), silver nanoparticles (AgNPs), or iron oxide nanoparticles (IONPs) using bisphosphonate-decorated nanoparticles (NPs) to prevent their aggregation and enzymeassisted cross-linking method to control the formation of the silk fibroin composite hydrogels in the presence of the NPs [80]. Confined alignment is another new method used to fabricate silk fibroin hydrogel with controlled molecular alignment and degree of crystallinity. This method enables the design and engineering of biopolymer-based materials with controlled hierarchical structure at multiple length scales and tunable properties [81].

Various forms of silk fibroin-based 3D materials such as porous scaffolds, sponges, foams, tubes, rods, and screws can be fabricated by several most widely adopt techniques including salt-leaching, gas foaming, freeze-drying, and electrospinning. In the salt-leaching method, salts are added to the silk fibroin solution, the mixture is then placed in a mold. After the mixture solution turns into gel, the salt is removed by immersing the mixture in water to obtain the salt-free 3D porous scaffolds. However, one major issue with this method is that the leaching of salt particles can lead to poor interconnection and abnormal pore shape. Gas foaming is a kind of method to create an interconnected pore structure with high porosity by rapid pressure relief around the liquefied polymer. Pore structure and porosity of the fabricated constructs can be tuned by varying the amount of gas in polymer. Freeze-drying is an important means to fabricate silk fibroin-based porous sponge scaffolds. The pore size and microstructures can be effectively controlled by adjusting the freezing temperature or silk fibroin concentration. Moreover, aligned scaffolds can be obtained by controlling the frozen conditions [2, 3, 82-85]. Besides these conventionally used methods, Guo et al. recently fabricated silk fibroin-based bulk materials including bars, rods, plates, tubes with caps, and screws with tunable mechanical properties via thermal processing for medical device applications. Specifically, amorphous silk nanomaterials reconstructed from the LiBr-silk fibroin solution were first produced, which were then processed into robust structural materials by hot pressing [86]. The method of $3 \mathrm{D}$ printing is also new, allowing the formation of silk fibroinbased 3D materials with biologically relevant structures in defined geometries with microscale resolution that are difficult or impossible to manufacture with conventional fabrication techniques. Based on the use of different silk fibroin solution inks such as the pure aqueous silk fibroin solution, 3D printing uses a silk fibroin solution incorporated with biologically active molecules and dopants, a self-curing silk fibroin solution, and a silk fibroin solution incorporated with living cells; and 3D printing in combination with sacrificial templating has been developed to fabricate $3 \mathrm{D}$ silk fibroin materials with complex structures down to the microscale (Figure 5) [87-91].

\section{B. mori silk fibroin materials applications}

Attractive properties including light weight, excellent mechanical property, flexibility, optical transparency, thermal stability, biocompatibility, controllable biodegradability, and versatility of silk fibroin along with progress in biomedicine and nanofabrication technologies have expanded the scope of functionalized silk fibroin-based materials applications to medical, electronic, optical, and filtration applications. 
a

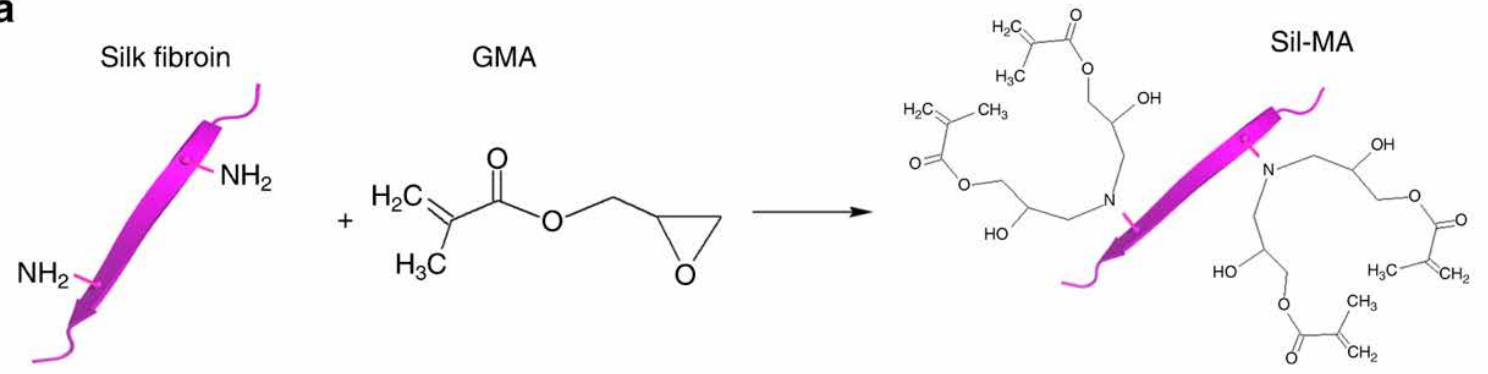

b

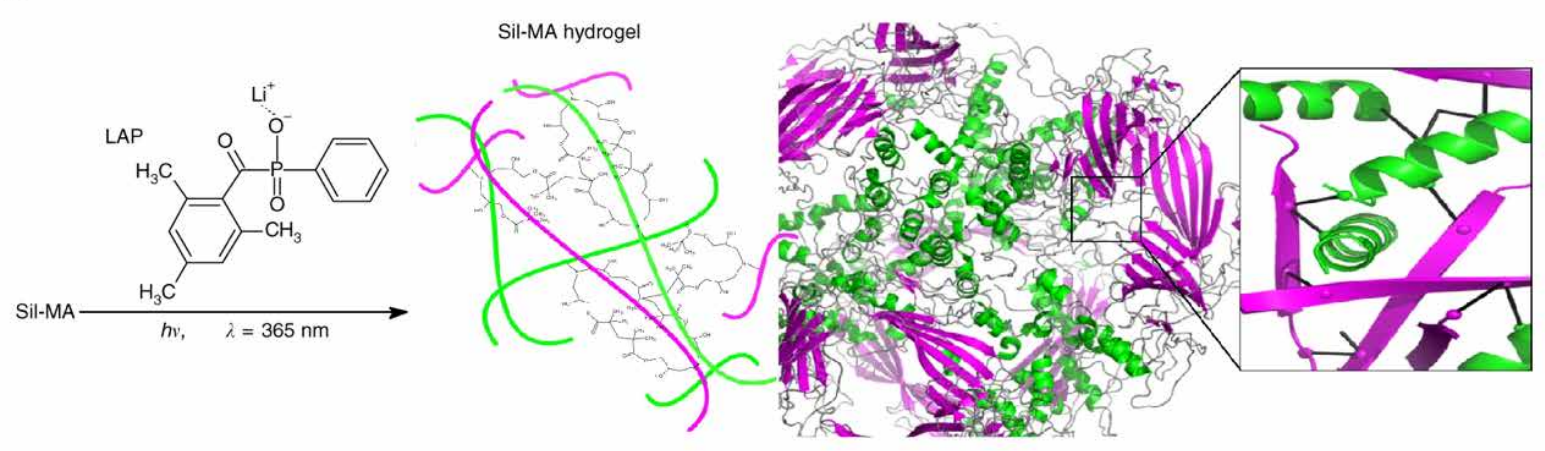

C
CAD
Printed images
Compression
Release

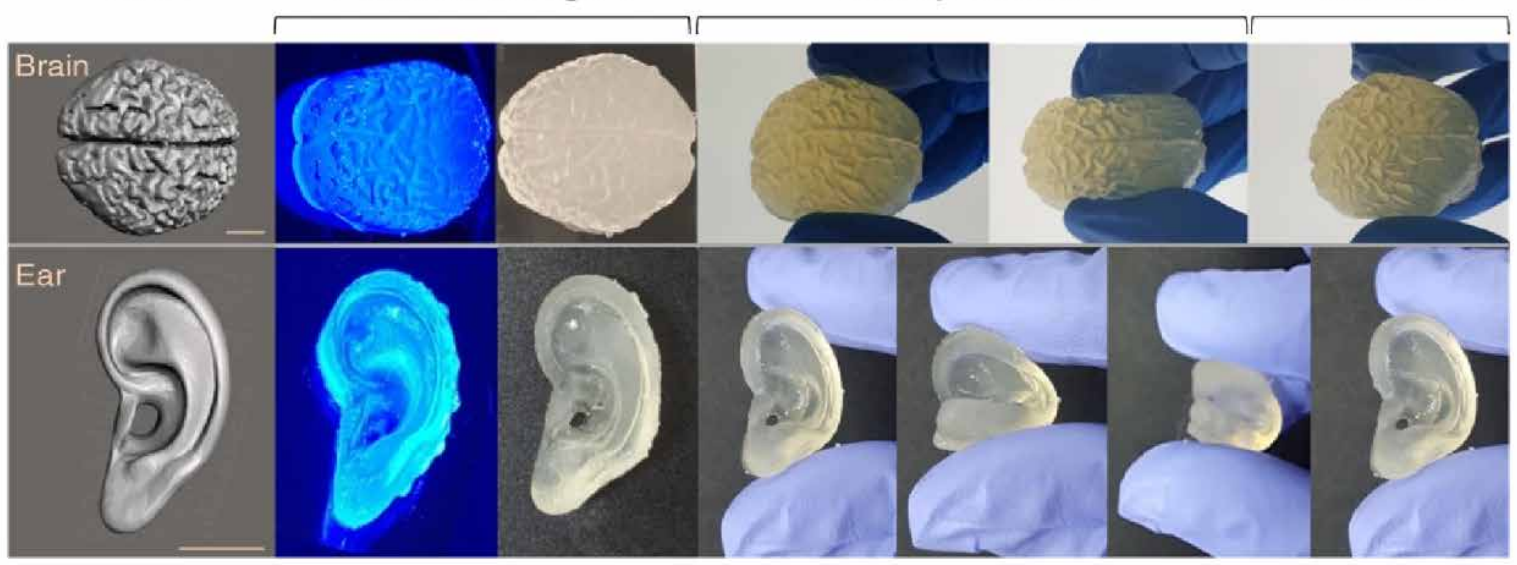

Figure 5. Digital light processing 3D printed silk fibroin hydrogel for tissue engineering. (a) Modification of silk fibroin molecule with glycidyl methacrylate (GMA). (b) Reaction process for the photopolymerization of Sil-MA in the presence of LAP photoinitiator and 3D structure of Sil-MA hydrogel formed via digital light process (DLP) printing. (c) CAD images and printed images of ear and brain. (Reproduced from [91]. CC BY 4.0.).

\subsection{Biomedical applications}

In the biomedical field, current routine clinical uses of silk fibroin, working directly with the degummed silk fiber, include silk surgical mesh for abdominal wall reconstruction and investigative plastic surgery applications, silk fabrics for the treatment of dermatological conditions, and silk sutures for use in general soft tissue approximating ligation. Present clinical trials using regenerated silk fibroin materials include water-resistant silk films for wound healing and thin silk films for acute and chronic tympanic membrane perforation repair [5]. In addition to these routine clinical uses and clinical trials, regenerated silk fibroin-based materials in a wide spectrum of formats have been investigated as tissue engineering scaffolds and drug carriers in biomedical applications in preclinical studies. Until now, SF has been fabricated in a variety of materials such as nanofibrous mats, hydrogels, and $3 \mathrm{D}$ porous scaffolds for use in the engineering and regeneration of a variety of tissues including skin, nerves, tendons, blood vessels, bone, cartilage, ligaments, and tendon (Table 3).

Electrospun silk fibroin nonwoven mats consisting of nanofibers are remarkable tissue engineering materials since their extracellular matrix (ECM)-like fibrous nature is suitable for cell interaction (Figure 6a) [92]. And functional silk fibroin nanofibrous mats can be fabricated by the incorporation of growth factors or other signaling factors $[62,96]$. By controlling the gelation process (Figure $6 \mathrm{~b}$ ), blending with other biopolymers (Figure $6 c$ ) and incorporating biologically functional moieties (Figure $6 \mathrm{~d}$ ), silk fibroin hydrogels or sponges with fine-tuned stiffness and optimized cell functions can be constructed for specialized tissue engineering applications [93-95]. Besides mainly being 
Table 3. List of tissue-engineered materials based on silk fibroin

\begin{tabular}{|c|c|c|c|}
\hline Material formats & Type of tissue engineered & Preparation methods & References \\
\hline Tube & Vascular graft & Electrospinning & 92 \\
\hline Hydrogel & Cartilage tissue & Bioprinting or freeze-drying & 93,94 \\
\hline Sponge & Bone tissue & Freeze-drying & 95 \\
\hline Nanofibrous mat & Skin tissue & Electrospinning & 96 \\
\hline Cylindrical scaffold & Nerve & Freezing-induced assembly & 97 \\
\hline Cylindrical scaffold & Tendon/ligament-to-bone tissue & Controlled freeze-drying & 98 \\
\hline $\begin{array}{c}\text { The collagen sponge permeated into the } \\
\text { rings of knitted silk mesh. }\end{array}$ & Anterior cruciate ligament & Knitting and freeze-drying & 99 \\
\hline
\end{tabular}

used as injectable tissue fillers, silk fibroin hydrogels with finely tuned properties can also be used for hard tissue regeneration $[79,80,94]$. Silk fibroin 3D biodegradable scaffolds taking the role of ECM analogues can serve as a necessary template or matrix supporting cell attachment, proliferation, differentiation, tissue neogenesis, formation of a new extracellular matrix, and transportation of nutrients and metabolic wastes [83-85, $94,95,98,99]$. It is worth noting that each type of engineered tissue should possess the correct balance of structural features and biological and mechanical properties for the induction of the desired cellular activity and to guide appropriate tissue regeneration.
Due to their combination of robust mechanical properties, controllable biodegradability and drug stabilization effect, silk fibroin-based materials have been investigated as sustainable drug delivery vehicles for a wide range of biological molecules including proteins, growth factors, peptides, and gene and therapeutic drugs such as anticancer agents and small molecule drugs [2, 66, 77]. Silk fibroin-based materials in the format of nanoparticles, electrospun nanofibrous mats, hydrogels, aerogels, coatings, and microneedles have been implemented as drug delivery platforms. Silk fibroin-based nanoparticles have been investigated as drug carriers due to their high binding capacity for various drugs, controlled drug release properties and mild preparation conditions.
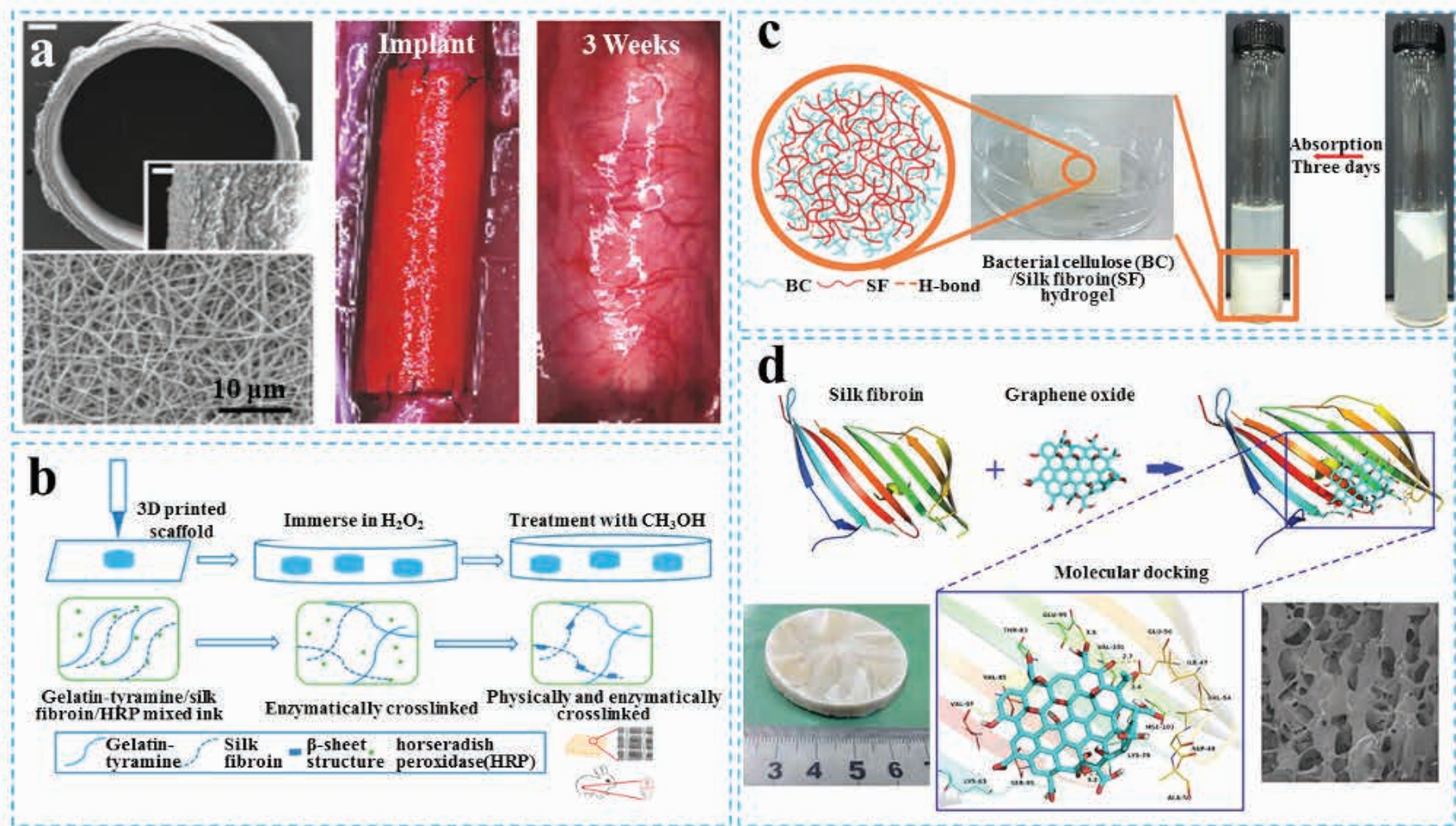

Figure 6. Schematic diagram of the silk fibroin-based materials for tissue engineering. (a) Small-diameter silk fibroin vascular grafts. (Reproduced from [92]. CC BY 4.0.). (b) 3D printed silk-gelatin hydrogel scaffold for cartilage regeneration. (Reproduced from [93]. CC BY 4.0.). (c) Bacterial cellulose/silk fibroin double network hydrogel for artificial cartilage. (Reproduced with permission [94]. Copyright 2019, Springer Nature B.V.). (d) Three-dimensional porous silk fibroin/graphene oxide scaffold. (Reproduced with permission [95]. Copyright 2019, Springer Nature B.V.). 
By developing green synthesis methods and adjusting the particle size, the chemical structure, and properties, modified or recombinant nontoxic silk fibroin-based nanoparticles can be designed to improve the therapeutic efficiency of drugs encapsulated into these nanoparticles [100-104]. Silk fibroinbased nanofibrous mats have been used as potential carriers for drug delivery due to higher drug encapsulation efficiency and better stability than other drug formulations. By manipulating the crystallinity and biodegradation rate of silk fibroin via functionalization and optimizing the porosity, morphology, and diameter of nanofibers, silk fibroin-based nanofibrous mats with controlled drug release and enhanced cell behaviors can be obtained (Figure 7a) [105]. Moreover, high porosity and good interconnectivity between the pores of electrospun nanofibrous mats make them suitable for use as mass transporters [106]. Silk fibroin hydrogel, with a microenvironment similar to the ECM, is often used as a drug carrier due to its high affinity to these drugs and its molecular permeability. Research has been focused on fabrication of silk fibroin-based composite hydrogels with tuned properties, stimuli responsiveness, and optimized treatment effect. Niu et al. fabricated a newer type of drug releasing enzymatically crosslinked hydrogel based on a semi-interpenetrating network of silk fibroin and poly(vinyl alcohol) (PVA) (Figure 7b). The fabricated composite hydrogel was found to possess lamellar structure and release properties [107]. Akrami-Hasan-Kohal, et al. fabricated a sonicationassisted cross-linking silk fibroin hydrogel/dexamethasone sodium phosphate loaded chitosan nanoparticles with ideal physical properties and long-term drug release [108]. Silk fibroin-based films and porous scaffolds such as aerogels have also been used as drug carriers because of their open-pore network and structure tenability. The porosity and surface area of the device may affect its drug release kinetics [109-111]. Silk fibroin coatings have also been combined with liposomes for long-term and targeted drug delivery (Figure 7c) [112, 113]. Due to its unique combination of favorable mechanical strength and ability to maintain the activity of encapsulated bioactive factors, the silk fibroin-based microneedles have been explored as a minimally invasive platform for delivering drugs or vaccines in a more patient-friendly manner. For example, Shin et al. fabricated oblique and sharp silk fibroin microneedles by digital light processing 3D printing for controllable transdermal drug delivery. The fabricated microneedles can realize effective transdermal delivery and controllable release of drug molecules [114]. Drug delivery devices made of silk fibroin may be found in a variety of material formats. Their choice depends on the mode of application, processability, desired release kinetics, and stability of the drug. Facile and green strategies should be developed to fabricate nontoxic silk fibroin-based materials with tunable properties and stimuli responsiveness for effective drug release.

\subsection{Electronic applications}

Flexible electronic devices are necessary for applications involving unconventional interfaces, such as soft and curved biological systems, where traditional silicon-based electronics present a mechanical mismatch [115]. By virtue of its light weight; excellent mechanical, dielectric, and optical properties; superior biosustainability and biodegradability; and ease of fabrication, silk fibroin has been utilized as the active element in the design of high-performance flexible electronics devices for a wide range of applications (Figure 8).

Silk fibroin has been combined with conductive materials such as carbon materials, ionic liquid, conducting polymers, and metal nanowires for sensor, electronic storage devices, electrodes, polymer electrolytes, and transient electronics applications, as listed in Table 4.

Although silk fibroin can be used as passive substrates and dielectric layers in electronic devices, the incorporated conductive components limited their biodegradability and bioresorbability for applications in biological systems [13, 115].

Table 4. List of flexible electronic devices based on silk fibroin materials

\begin{tabular}{|c|c|c|c|}
\hline Material formats & Potential applications & Working mechanism & References \\
\hline Silk fibroin/graphene film & Humidity sensor & $\begin{array}{c}\text { Water content in the film causes } \\
\text { change in resistance }\end{array}$ & 116 \\
\hline $\begin{array}{c}\text { MXene coated silk fibroin nanofiber } \\
\text { membrane and MXene ink-printed } \\
\text { silk fibroin interdigitated electrode }\end{array}$ & Medical pressure sensor & Resistance change upon pressure & 117 \\
\hline Silk fibroin hydrogel ionotronics & $\begin{array}{c}\text { Environmental monitoring and } \\
\text { communications }\end{array}$ & $\begin{array}{c}\text { Resistance change upon } \\
\text { temperature and/or humidity change }\end{array}$ & 118 \\
\hline $\begin{array}{c}\text { Soft conductive hydrogel } \\
\text { triboelectric nanogenerators } \\
\text { carbon nanotube composite film }\end{array}$ & $\begin{array}{c}\text { Strain or pressure causes change in } \\
\text { resistance }\end{array}$ & 119 \\
\hline Silk fibroin-based film & Electrolytes & Electric heating behavior & 120 \\
\hline
\end{tabular}




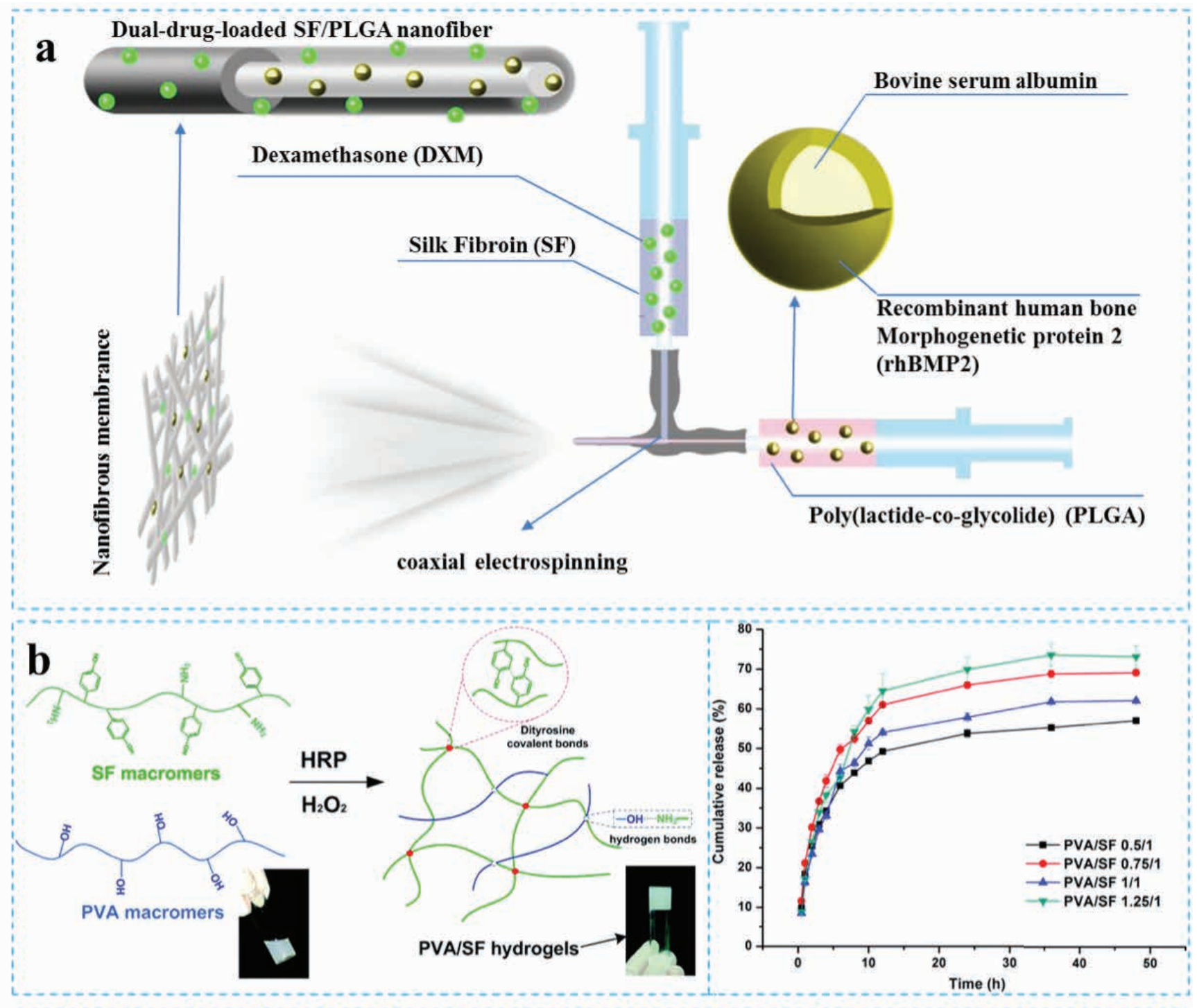

\section{c Mixture}

bmSF molecules

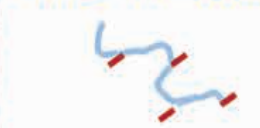

bmSF nanospheres

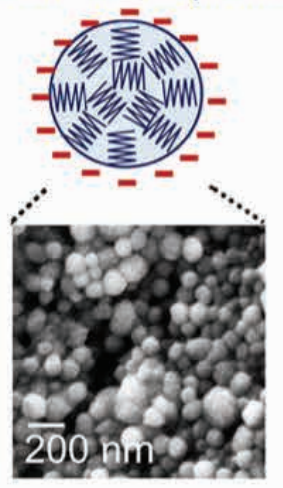

bmSF (random coil) WM $b m S F$ ( $\beta$-sheet)
Electro-gel
Electro-gel

Coating
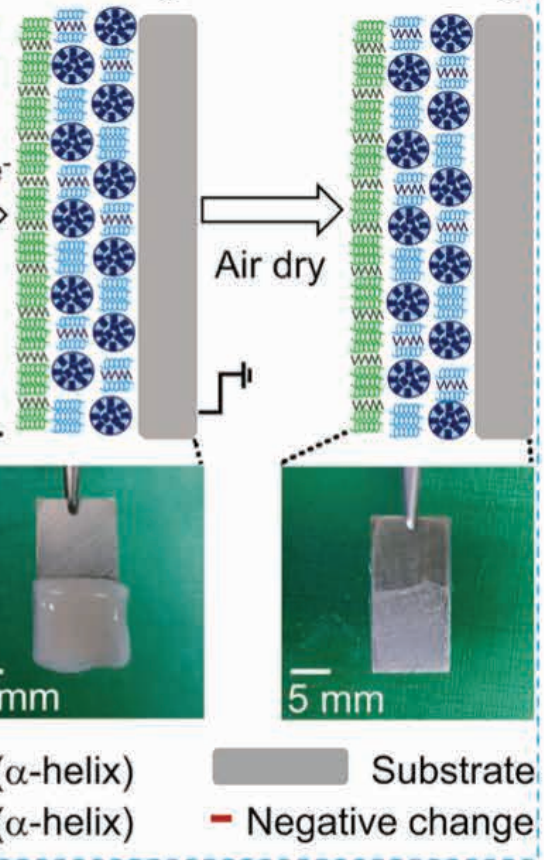

Figure 7. Schematic diagram of the silk fibroin-based materials for drug release. (a) Dual-drug-loaded SF/PLGA scaffolds for bone regeneration. (Reproduced from [105]. CC BY 4.0.). (b) PVA/SF enzymatically crosslinked semi-interpenetrating hydrogel for hydrophobic drug delivery. (Reproduced from [107]. CC BY 4.0.). (c) Multi-layered silk fibroin coatings for controlled release of drug. (Reproduced from [112]. CC BY 4.0.). 

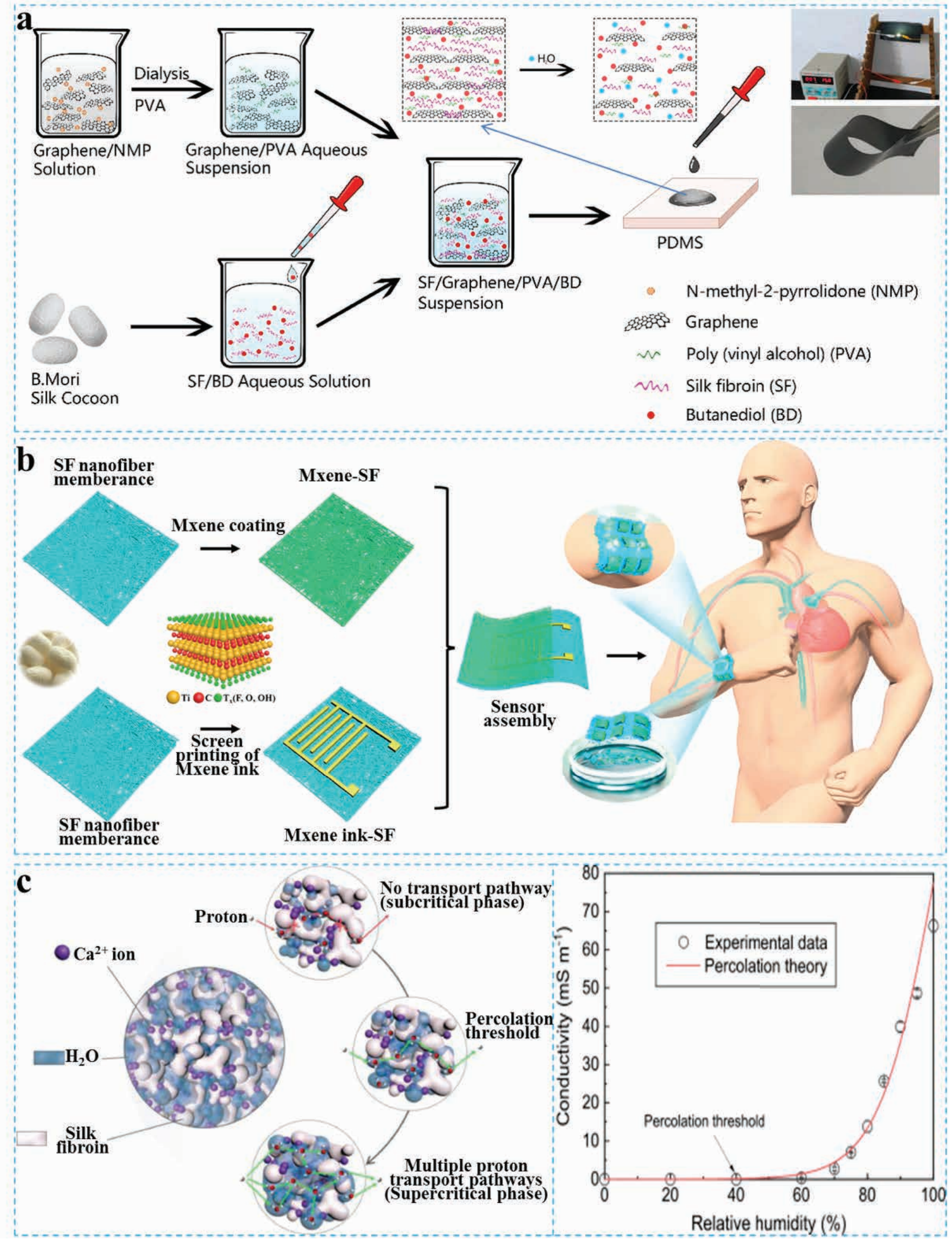

Figure 8. Schematic diagram of the silk fibroin-based materials for flexible electronics devices. (a) SF/Graphene film-based humidity sensor. (Reproduced from [116]. CC BY 4.0.). (b) MXene/SF nanocomposites-based pressure sensor. (Reproduced with permission [117]. Copyright 2021, American Chemical Society). (c) SF hydrogel ionotronics-based temperature and humidity sensor. (Reproduced from [118]. CC BY 4.0.). 


\subsection{Optical applications}

In addition to applications in electronic devices, silk fibroin has also been heavily investigated as an interesting optical material because of its high transparency and excellent mechanical properties. Silk fibroin has been used in a variety of optical devices, such as optical diffraction-based sensors, optical waveguides, optical gazes, and 3D photonics. For example,
Zhou et al. fabricated a set of bioactive optical diffraction-based sensors microfabricated using functionalized silk fibroin films for optical diffraction-based sensing applications, including hydration sensing, biological concealment, therapeutic treatment, and in vitro and in vivo drug release monitoring upon degradation. Their work sheds light on a new class of transient optical devices-with specific functionalitiesthat can physically degrade in the body or disappear in the

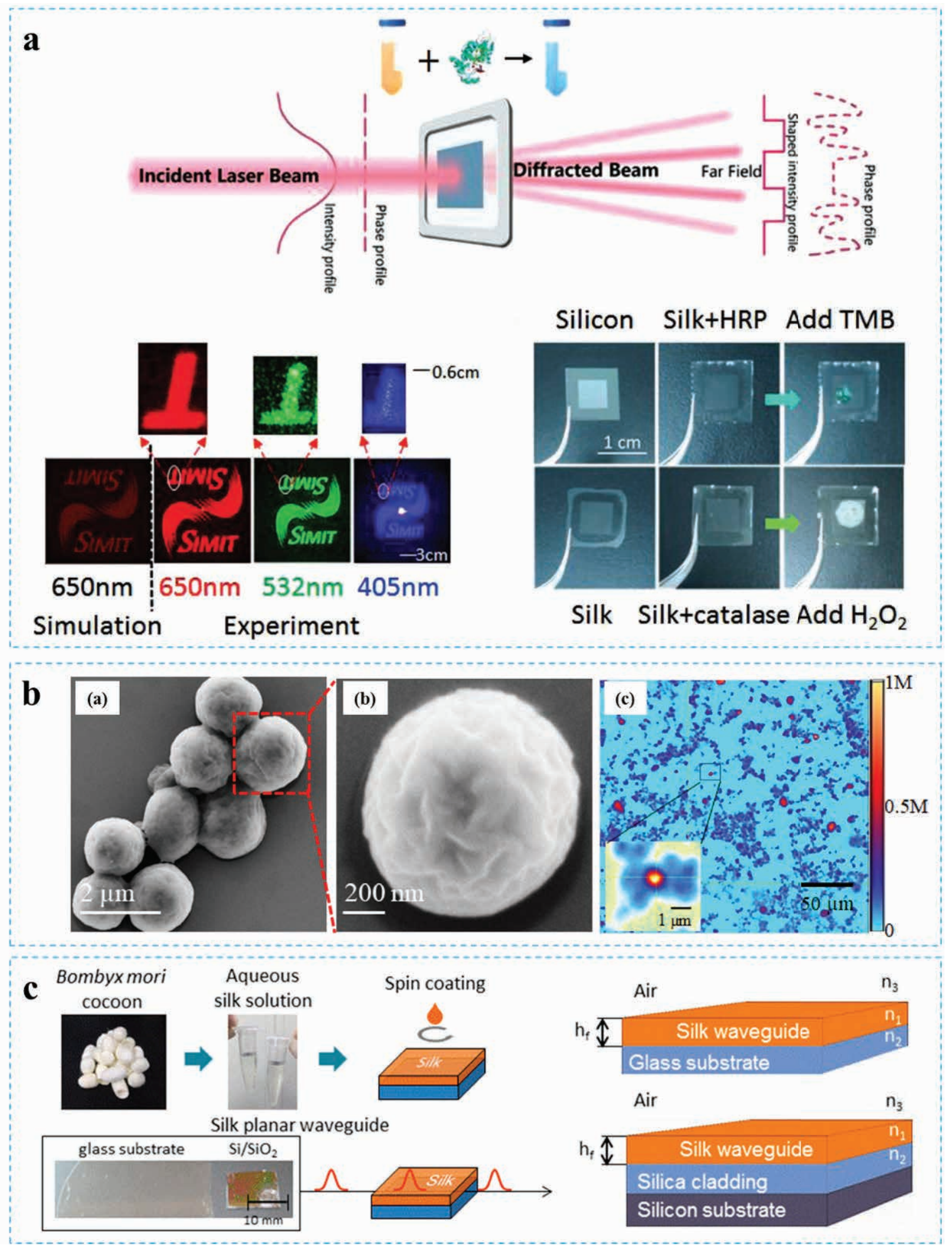

Figure 9. Schematic diagram of the silk fibroin-based materials for optical devices. (a) 2D phase-shifting binary diffractive optical element made of regenerated silk fibroin films. (Reproduced with permission [122]. Copyright 2017, John Wiley and Sons). (b) silk fibroin-coated magnesium oxide nanospheres for noninvasive bioimaging applications. (Reproduced from [123]. CC BY 4.0.). (c) silk optical planar waveguide. (Reproduced from [125]. CC BY 4.0.). 
environment at prescribed times and at controlled rates (Figure 9a) [122]. Li et al. fabricated silk fibroin-coated magnesium oxide nanospheres for noninvasive bioimaging applications (Figure 9b) [123]. The biocompatibility of waveguide material is important when it needs to interface directly with living cells in biomedical applications. Biocompatible silk fibroin-based optical waveguides have been produced by Santos et al. using direct laser writing and Prajzler using direct depositing (Figure 9c), respectively [124, 125]. Lee et al. fabricated silk fibroin films and patterned them into different nanostructures via tipenhanced near-field infrared nanolithography for rewritable optical storage medium [73].

\subsection{Filtration systems}

Among various material formats, materials prepared from electrospun nanofibers have properties such as high surface-to-volume ratio, low pressure drop, and controllable morphology and connectivity, making them attractive for achieving excellent filtering performance. Because of their biocompatibility, biodegradability, and nontoxicity, silk fibroin materials in the form of electrospun nanofibrous mats have also been investigated as filtration systems for water treatment and air filtration. For example, Garrido et al. fabricated electrospun silk fibroin/ZnO mats to remove pesticide residues from water under natural sunlight [126]. Zhou et al fabricated a silk fibroingraphene oxide functionalized melamine sponge for efficient oil absorption and oil and water separation [127]. Wang, et al. fabricated porous $\mathrm{ZnS}$ and $\mathrm{ZnO}$ films using silk fibroin as a template by coaxial electrospinning for highly efficient photodegradation of organic dyes (Figure 10a) [128]. Gao et al., [129] Min et al., [130] respectively fabricated electrospun silk nanofibers for efficient PM 2.5 and submicron particles capture (Figure 10b). Multifunctional silk fibroin nanofiberbased systems showed superior filtration performance with a much lower basis weight compared with commercial filters and absorbents. Yet, further efforts should be devoted to enhance the mechanical properties of the nanofibers for longer life and design more advanced filtration system.

\section{Conclusion and outlook}

The ubiquity, unique hierarchical structure, light weight, excellent mechanical property, flexibility, optical transparency, thermal stability, biocompatibility, controllable biodegradability, versatility in material format design, and mild aqueous processing of silk fibroin make silk fibroin-based materials an attractive biomaterial for various applications. Great efforts have been made to develop green and facile technologies for reverse-engineered silk fibroin extraction and materials fabrication. Silk fibroin-based materials in versatile formats, including fibers, particles, films, hydrogels, and 3D materials, have been developed for advanced utilities in medical, electronic, optical, and filtration applications. Bionanotechnology such as nanoimprinting/patterning, confined alignment, and 3D printing will further provide synergies for the prospective development of silk fibroin-based materials in related applications. Nevertheless, despite the immense level of development of silk fibroin-based materials, challenges in the large-scale production of silk fibroin and the control over the nanostructure of silk fibroin-based materials remain. Most of silk fibroin materials-processing techniques are still timeand solvent-intensive. Better control over the hierarchical
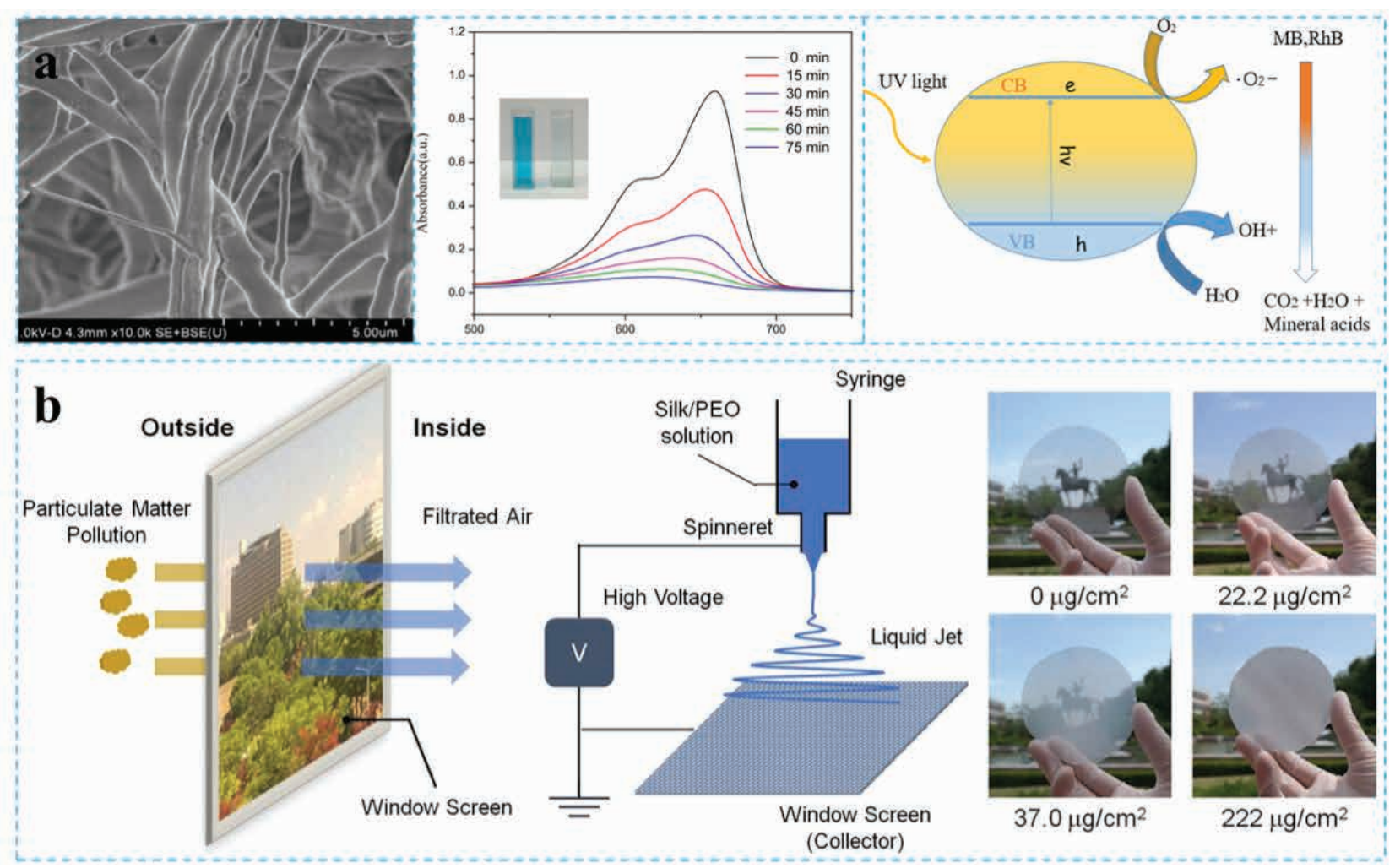

Figure 10. Schematic diagram of the silk fibroin-based materials for filtration systems. (a) Porous ZnS and ZnO films using silk fibroin as a template by coaxial electrospinning for highly efficient photodegradation of organic dyes. (Reproduced with permission [128]. Copyright 2018, John Wiley and Sons). (b) Optically translucent silk nanofibrous air filter. (Reproduced from [130]. CC BY 4.0.) 
structure to produce structurally and functionally optimized silk nanomaterials for specific applications is still a problem.

\section{Acknowledgments}

This work has been financially supported by the Open Project Program of Key Laboratory of Yarn Materials Forming and Composite Processing Technology (No. MTC2021-04) and the Jiaxing Public Welfare Technology Application Research Project (No. 2021AD10012) of Zhejiang Province. The authors also acknowledge the financial support from the Natural Science Foundation (No. BK20201216), High Education Science Foundation (No. 19KJD540001 \& 21KJB540007), and Qinglan Project (No. Jiangsu Teacher 2019-3) of Jiangsu Province. The authors are grateful for the the Open Project Program of Engineering Research Center for Clean Production of Textile Printing and Dyeing, Ministry of Education (No. FZYR2021002 \& FZYR2021003).

\section{References}

[1] Ray, M., Gangopadhyay, D. (2021). Effect of maturation stage and sex on proximate, fatty acid and mineral composition of eri silkworm (Samia ricini) from India. Journal of Food Composition and Analysis, 100, 103898.

[2] Nguyen, T. P., et al. (2019). Silk fibroin-based biomaterials for biomedical applications: A review. Polymers, 11(12), 1933.

[3] Wang, H. Y., Zhang, Y. Q., Wei, Z. G. (2021). Dissolution and processing of silk fibroin for materials science. Critical Reviews in Biotechnology, 41(3), 406-424.

[4] Gore, P. M., Naebe, M., Wang, X., Kandasubramanian, $B$. (2019). Progress in silk materials for integrated water treatments: Fabrication, modification and applications. Chemical Engineering Journal, 374, 437-470.

[5] Sun, W., Gregory, D. A., Tomeh, M. A., Zhao, X. (2021). Silk fibroin as a functional biomaterial for tissue engineering. International Journal of Molecular Sciences, 22(3), 1,499.

[6] Zhang, Y., Wu, R., Patil, A., Ma, L., Yu, R., Yu, W. D., Liu, X. Y. (2021). Enhanced mechanical performance of biocompatible silk fibroin films through mesoscopic construction of hierarchical structures. Textile Research Journal, 91(9-10), 1146-1154.

[7] Bruder, V., Ludwig, T., Opitz, S., Christoffels, R., Fischer, T., Maleki, H. (2021) Hierarchical assembly of surface modified silk fibroin biomass into micro-, and milli-metric hybrid aerogels with core-shell, janus, and composite configurations for rapid removal of water pollutants. Advanced Materials Interfaces, 8(5), 2001892.

[8] Crivelli, B., et al. (2018). Silk nanoparticles: From inert supports to bioactive natural carriers for drug delivery. Soft Matter, 14, 546-557.

[9] Nguyen, A. T., Huang, Q. L., Yang, Z., Lin, N., Xu, G., Liu, X. Y. (2015). Crystal networks in silk fibrous materials: From hierarchical structure to ultra performance. Small, 11(910), 1039-1054.

[10] Wongpinyochit, T., Johnston, B. F., Seib, F. P. (2018). Degradation behavior of silk nanoparticles-enzyme responsiveness. ACS Biomaterials Science \& Engineering, 4(3), 942-951.
[11] Bucciarelli, A., Greco, G., Corridori, I., Pugno, N. M., Motta, A. (2021). A design of experiment rational optimization of the degumming process and its impact on the silk fibroin properties. ACS Biomaterials Science \& Engineering, 7(4), 1374-1393.

[12] Wani, S. U. D., Gautam, S. P., Qadrie, Z. L., Gangadharappa, H. V. (2020). Silk fibroin as a natural polymeric based bio-material for tissue engineering and drug delivery systems-A review. International Journal of Biological Macromolecules, 163, 2145-2161.

[13] Koh, L. D., Yeo, J., Lee, Y. Y., Ong, Q., Han, M., Tee, B. C. K. (2018). Advancing the frontiers of silk fibroin proteinbased materials for futuristic electronics and clinical wound-healing (Invited review). Materials Science and Engineering: C, 86, 151-172.

[14] Volkov, V., Ferreira, A. V., Cavaco-Paulo, A. (2015). On the routines of wild-type silk fibroin processing toward silkinspired materials: A review. Macromolecular Materials and Engineering, 300(12), 1199-1216.

[15] Rastogi, S., Kandasubramanian, B. (2020). Processing trends of silk fibers: Silk degumming, regeneration and physical functionalization. The Journal of The Textile Institute, 111(12), 1794-1810.

[16] Gulrajani, M. L. (1992). Degumming of silk. Coloration Technology, 22(1), 79-89.

[17] Chopra, S., Gulrajani, M. L. (1994). Comparative evaluation of the various methods of degumming silk. Indian Journal of Fibre \& Textile Research, 1994, 19, 76-83.

[18] Yuksek, M., Kocak, D., Merdan, N. (2012). Effect of degumming performed with different type natural soaps and through ultrasonic method on the properties of silk fiber. Advances in Environmental Biology, 6(2), 801-808.

[19] Kim, H. J., Kim, M. K., Lee, K. H., Nho, S. K., Han, M. S., Um, I. C. (2017). Effect of degumming methods on structural characteristics and properties of regenerated silk. International Journal of Biological Macromolecules, 104(Pt A), 294-302.

[20] Jiang, P., Liu, H., Wang, C., Wu, L., Huang, J., Guo, C. (2006). Tensile behavior and morphology of differently degummed silkworm (Bombyx mori) cocoon silk fibres. Materials Letters, 60(7), 919-925.

[21] Rehman, R., Mahmud, S., Habib, M. A., Islam, A. (2015). A revolution of silk dyeing with $F L$ based cotton-reactive dyes. International Journal of Textile Science, 4(2), 42-52.

[22] Ngoka, B. M., Nguku, E. K., Kioko, E. N., Raina, S. K., Mueke, J. M. (2015). Extraction of natural silk fibre from cocoons of argema mimosa (Lepidoptera: Saturniidae). Journal of Agricultural Science and Technology A, 5, 846853.

[23] Dong, X., Xing, T. L., Chen, G. Q. (2011). Influence of degumming methods on mechanical properties of silk and CODcr of wastewater. Advanced Materials Research, 332334, 183-187.

[24] Freddi, G., Mossotti, R., Innocenti, R. (2003). Degumming of silk fabric with several proteases. Journal of Biotechnology, 106(1), 101-112.

[25] Arami, M., Rahimi, S., Mivehie, L., Mazaheri, F., Mahmoodi, N. M. (2007). Degumming of Persian silk with mixed proteolytic enzymes. Journal of Applied Polymer Science, 106(1), 267-275. 
[26] Gulrajani, M. L., Malik, R. (1993). Degumming of silk with methylamine. Indian Journal of Fibre \& Textile Research, 18, 72-78.

[27] Gulrajani, M. L., Sinha, S. (1993). Studies in degumming of silk with aliphatic amines. Journal of the Society of Dyers and Colourists, 109(7-8), 256-260.

[28] Anand, P., Pandey, J. P., Pandey, D. M. (2021). Study on cocoonase, sericin, and degumming of silk cocoon: Computational and experimental. Journal of Genetic Engineering and Biotechnology, 19, 32.

[29] Wang, H. Y., Zhang, Y. Q. (2013). Effect of regeneration of liquid silk fibroin on its structure and characterization. Soft Matter, 9, 138-145.

[30] Javalim U.C., Padaki, N.V., Das, B., Malali, K.B. (2015). Developments in the use of silk by-products and silk waste. Woodhead Publishing (Cambridge), 88-111.

[31] Wang, F., Cao, T. T., Zhang, Y. Q. (2015). Effect of silk protein surfactant on silk degumming and its properties. Materials Science and Engineering: C, 55, 131-136.

[32] Zhao, Z. L., Zhang, Y. Q. (2020). Greener degumming production of layered sericin peptides from a silkworm cocoon and their physicochemical characteristics and bioactivities in vitro. Journal of Cleaner Production, 261, 121080

[33] Zhang, H., Li, H., Liu, H., Lang, D. A., Xu, H., Zhu, H. (2019). Degumming raw silk by a halotolerant metalloprotease isolated from metabolites of Vibrio sp. LA-05. International Biodeterioration \& Biodegradation, 142, 124-130.

[34] Rahman, M., Bhowmik, A., Das, S., Chowhan, K., Biswas, T. (2020). Green degumming of silk by enzyme extracted from natural sources. Journal of Materials Science and Chemical Engineering, 8, 30-40.

[35] Prathumpai, W., Promboon, A., Werapan, B., Nutaratat, P., Chim-Anek, P., Ninpetch, U. (2020). Pilot-scale protease production by Bacillus sp. C4 for silk degumming processes. Journal of Natural Fibers, DOI: 10.1080/15440478.2020.1788482.

[36] Zhao, Z. L., Li, W. W., Wang, F., Zhang, Y. Q. (2018). Using of hydrated lime water as a novel degumming agent of silk and sericin recycling from wastewater. Journal of Cleaner Production, 172, 2090-2096.

[37] Wang, F., Zhang, Y. Q. (2017). Effects of alkyl polyglycoside [APG] on Bombyx mori silk degumming and the mechanical properties of silk fibroin fibre. Materials Science and Engineering: C, 74, 152-158.

[38] Haggag, K., El-Sayed, H., Allam, O. G. (2007). Degumming of silk using microwave-assisted treatments. Journal of Natural Fibers, 4(3): 1-22.

[39] Mahmoodi, N. M., Moghimi, F., Arami, M., Mazaheri, F. (2010). Silk degumming using microwave irradiation as an environmentally friendly surface modification method. Fibers and Polymers, 11(2): 234-240.

[40] Gupta, D., Agrawal, A. Chaudhary, H., Gulrajani, M., Gupta, C. (2013). Cleaner process for extraction of sericin using infrared. Journal of Cleaner Production, 52, 488-494.

[41] Vyas, S. K., Shukla, S. R. (2016). Comparative study of degumming of silk varieties by different techniques. Journal of the Textile Institute, 107(2), 191-199.

[42] Cai, Y., Ge, H. Y., Liu, J. Q. (2012). A study on ultrasonic technology in silk degumming. Advanced Materials Research, 441, 122-126.
[43] Lo, C. H. (2021). Degumming silk by $\mathrm{CO}_{2}$ supercritical fluid and their dyeing ability with plant indigo. International Journal of Clothing Science and Technology, 33(3): 465476.

[44] Cao, T. T., Wang, Y. J., Zhang, Y. Q. (2013). Effect of strongly alkaline electrolyzed water on silk degumming and the physical properties of the fibroin fiber. PLoS ONE,8(6), e65654.

[45] Wang, R., Zhu, Y., Shi, Z., Jiang, W., Liu, X., Ni, Q. Q. (2018). Degumming of raw silk via steam treatment. Journal of Cleaner Production, 203: 492-497.

[46] Wang, H. Y., Wei, Z. G., Zhang, Y. Q. (2020). Dissolution and regeneration of silk from silkworm Bombyx mori in ionic liquids and its application to medical biomaterials. International Journal of Biological Macromolecules, 143, 594-601.

[47] Cao, K., Liu, Y., Ramakrishna, S. (2017). Recent developments in regenerated silk fiber. Journal of Nanoscience and Nanotechnology, 17(12), 8667-8682.

[48] Correa, E. E., Lopera, D. O. G., Restrepo, S. G., OssaOrozco, C. P. (2020). Effective sericin-fibroin separation from Bombyx mori silkworms fibers and low-cost salt removal from fibroin solution. Revista Facultad de Ingeniería, Universidad de Antioquia, 94, 97-101.

[49] Huang, J., et al. (2020). Facile preparation of a strong chitosan-silk biocomposite film. Carbohydrate Polymers, 229, 1115515.

[50] Samie, M., Muhammad, N., Yameen, M. A., Chaudhry, A. A., Khalid, H., Khan, A. F. (2020). Aqueous solution of a basic ionic liquid: A perspective solvent for extraction and regeneration of silk powder from Bombyx mori silk cocoons. Journal of Polymers and the Environment, 28, 657-667.

[51] Xie, C., Li, W., Liang, Q., Yu, S., Li, L. (2019). Fabrication of robust silk fibroin film by controlling the content of $\beta$-sheet via the synergism of UV-light and ionic liquids. Applied Surface Science, 492, 55-65.

[52] Wang, H. Y., Zhang, Y. Q., Wei, Z. G. (2020). Excess acetone extraction in silk protein solution greatly accelerates the regeneration progress of silk fibroin for desalting and purification. International Journal of Biological Macromolecules, 146: 588-595.

[53] Fydrych, M., Greenhalgh, A., Vollrath, F. (2019). Artificial spinning of natural silk threads. Scientific Reports, 9, 15428.

[54] Wang, S. D., Ma, Q., Wang, K., Chen, H. W. (2018). Improving antibacterial activity and biocompatibility of bioinspired electrospinning silk fibroin nanofibers modified by graphene oxide. ACS Omega, 3(1), 406-413.

[55] Chomachayi, M. D., Jalali-arani, A., Urreaga, J. M. (2020). The effect of silk fibroin nanoparticles on the morphology, rheology, dynamic mechanical properties, and toughness of poly(lactic acid)/poly(E-caprolactone) nanocomposite. Journal of Applied Polymer Science, 137(40): 49232.

[56] Zhang, F., You, X., Dou, H., Liu, Z., Zuo, B., Zhang, X. (2015). Facile fabrication of robust silk nanofibril films via direct dissolution of silk in $\mathrm{CaCl}_{2}$-formic acid solution. ACS Applied Materials \& Interfaces, 7(5): 3352-3361.

[57] Gu, X., et al. (2021). Pure-silk fibroin hydrogel with stable aligned micropattern toward peripheral nerve regeneration. Nanotechnology Reviews, 10, 10-19. 
[58] Lovati, A. B., et al. (2020). Peptide-enriched silk fibroin sponge and trabecular titanium composites to enhance bone ingrowth of prosthetic implants in an ovine model of bone gaps. Frontiers in Bioengineering and Biotechnology, 8, 563203.

[59] Guo, C., Li, C., Mu, X., Kaplan D. L. (2020). Engineering silk materials: From natural spinning to artificial processing. Applied Physics Reviews, 7, 011313.

[60] Ma, Q., Yang, B., Li, H. H, Guo, J. J, Zhao, S. Q, Wu, G. $H$, (2021). Preparation and properties of photochromic regenerated silk fibroin/Tungsten trioxide nanoparticles hybrid fibers. Composites Communications, 27, 100810.

[61] Abdel-Mohsen, A. M., Jancar, J., Kalina, L., Hassan, A. F. (2020). Comparative study of chitosan and silk fibroin staple microfibers on removal of chromium (VI): Fabrication, kinetics and thermodynamic studies. Carbohydrate Polymers, 234, 115861.

[62] Mostafavi, P., Naeimi, M. (2021). Investigation of vitamin $D$-loaded silk fibroin electrospun scaffolds for bone tissue engineering applications. Materials Technology, DOI: 10.1080/10667857.2021.1940426.

[63] Mercado, J., et al. (2020). Regenerated silk fibers obtained by straining flow spinning for guiding axonal elongation in primary cortical neurons. ACS Biomaterials Science \& Engineering, 6(12), 6842-6852.

[64] Wang, Q., et al. (2020). Observations of $3 \mathrm{~nm}$ Silk Nanofibrils Exfoliated from Natural Silkworm Silk Fibers. ACS Materials Letters, 2(2), 153-160.

[65] Uddin, M. G., et al. (2020). Preparing Bombyx mori silk nanofibers using a sustainable and scalable approach. ACS Sustainable Chemistry \& Engineering, 8(2), 11551162.

[66] Tomeh, M. A., Hadianamrei, R., Zhao, X. (2019). Silk fibroin as a functional biomaterial for drug and gene delivery. Pharmaceutics, 11(10), 494.

[67] Xiao, M., Lv, S. (2019). Self-assembled regenerated silk fibroin microsphere-embedded $\mathrm{Fe}_{3} \mathrm{O}_{4}$ magnetic nanoparticles for immobilization of Zymolyase. ACS Omega, 4(25), 21612-21619.

[68] Carissimi, G., Lozano-Pérez, A. A., Montalbán, M. G., Aznar-Cervantes, S. D., Cenis, J. L., Villora, G. (2019). Revealing the influence of the degumming process in the properties of silk fibroin nanoparticles. Polymers, 11(12): 2045.

[69] Gou, S., et al. (2019). Multi-bioresponsive silk fibroinbased nanoparticles with on-demand cytoplasmic drug release capacity for $C D 44$-targeted alleviation of ulcerative colitis. Biomaterials, 212, 39-54.

[70] Baruah, R. R., Kalita, M. C., Devi, D. (2020). Novel nonmulberry silk fibroin nanoparticles with enhanced activity as potential candidate in nanocarrier mediated delivery system. RSC Advances, 15(10), 9070-9078.

[71] Wang, Y., Zheng, Z., Cheng, Q., Kaplan, D. L., Li, G., Wang, $X$. (2020). Ductility and porosity of silk fibroin films by blending with glycerol/polyethylene glycol and adjusting the drying temperature. ACS Biomaterials Science \& Engineering, 6(2): 1176-1185.

[72] Humenik, M., Winkler, A., Scheibel, T. (2021). Patterning of protein-based materials. Biopolymers, 112(2), e23412.

[73] Lee, W., et al. (2020). A rewritable optical storage medium of silk proteins using near-field nano-optics. Nature Nanotechnology, 15, 941-947.
[74] You, R., Li, X., Luo, Z., Qu, J., Li, M. (2015). Directional cell elongation through filopodia-steered lamellipodial extension on patterned silk fibroin films. Biointerphases, 10(1): 011005.

[75] Kim, S., et al. (2014). All-water-based electron-beam lithography using silk as a resist. Nature Nanotechnology, 9, 306-310.

[76] Park, J., et al. (2016). Eco-friendly photolithography using water-developable pure silk fibroin. RSC Advances, 45(6): 39330-39334.

[77] Zheng, H., Zuo, B. (2021). Functional silk fibroin hydrogels: Preparation, properties and applications. Journal of Materials Chemistry B, 9: 1238-1258.

[78] Seib, F. P. (2018). Reverse-engineered silk hydrogels for cell and drug delivery. 2018. Therapeutic Delivery, 9(6), 469-487.

[79] Hasturk, O., et al. (2020). Enzymatically crosslinked silk and silk-gelatin hydrogels with tunable gelation kinetics, mechanical properties and bioactivity for cell culture and encapsulation. Biomaterials, 232, 119720.

[80] Marín, C. B., et al. (2021). Gold, silver, and iron oxide nanoparticle incorporation into silk hydrogels for biomedical applications: elaboration, structure, and properties. ACS Biomaterials Science \& Engineering, 7(6), 2358-2371.

[81] Tseng, P., et al. (2017). Directed assembly of bioinspired hierarchical materials with controlled nanofibrillar architectures. Nature Nanotechnology, 12, 474-480.

[82] Reizabal, A., et al. (2021). Processing strategies to obtain highly porous silk fibroin structures with tailored microstructure and molecular characteristics and their applicability in water remediation. Journal of Hazardous Materials, 403, 123675.

[83] Cheng, G., et al. (2018). Advanced silk fibroin biomaterials for cartilage regeneration. ACS Biomaterials Science \& Engineering, 4(8), 2704-2715.

[84] Hokmabad, V. R., Davaran, S., Ramazani, A., Salehi, R. (2017). Design and fabrication of porous biodegradable scaffolds: a strategy for tissue engineering. Journal of Biomaterials Science, Polymer Edition, 28(16), 1797-1825.

[85] Yang, Y., Spessot, E., Motta, A. (2021). Silk fibroin-based soft biomaterial/scaffolds for tissue engineering strategies. Royal Society of Chemistry (London), 88-111.

[86] Guo, C., et al. (2020). Thermoplastic moulding of regenerated silk. Nature Materials, 19, 102-108.

[87] Agostinacchio, F., Mu, X., Dirè, S., Motta, A., Kaplan, D. L. (2021). In situ 3D printing: Opportunities with silk inks. Trends in Biotechnology, 39(7), 719-730.

[88] Wang, Q., Han, G., Yan, S., Zhang, Q. (2019). 3D printing of silk fibroin for biomedical applications. Materials, 12(3), 504.

[89] Rodriguez, M. J., Dixon, T. A., Cohen, E., Huang, W., Omenetto, F. G., Kaplan, D. L. (2018). 3D freeform printing of silk fibroin. Acta Biomaterialia, 71, 379-387.

[90] DeBari, M. K., Keyser, M. N., Bai, M. A. Abbott, R. D. (2020). $3 D$ printing with silk: Considerations and applications. Connective Tissue Research, 61(2), 163-173.

[91] Kim, S. H., et al. (2018). Precisely printable and biocompatible silk fibroin bioink for digital light processing 3D printing. Nature Communications, 9, 1620. 
[92] Chan, A. H. P., et al. (2019). Altered processing enhances the efficacy of small-diameter silk fibroin vascular grafts. Scientific Reports, 9, 17461.

[93] Li, Q., et al. (2021). 3D printed silk-gelatin hydrogel scaffold with different porous structure and cell seeding strategy for cartilage regeneration. Bioactive Materials, 6, 3396-3410.

[94] Wang, K., Ma, Q., Zhang, Y. M., Han, G. T., Qu, C. X., Wang, S. D. (2020). Preparation of bacterial cellulose/silk fibroin double-network hydrogel with high mechanical strength and biocompatibility for artificial cartilage. Cellulose, 27, 1845-1852.

[95] Wang, S. D., Ma, Q., Wang, K., Ma, P. B. (2018). Strong and biocompatible three-dimensional porous silk fibroin/ graphene oxide scaffold prepared by phase separation. International Journal of Biological Macromolecules, 111, 237-246.

[96] Yin, J., Fang, Y., Xu, Y., Ahmed, A. (2021). High-throughput fabrication of silk fibroin/hydroxypropyl methylcellulose (SF) HPMC) nanofibrous scaffolds for skin tissue engineering. International Journal of Biological Macromolecules, 183, 1210-1221.

[97] Li, X., et al. (2019). Water-stable silk fibroin nerve conduits with tunable degradation prepared by a mild freezinginduced assembly. Polymer Degradation and Stability, 164, 61-68.

[98] Tellado, S. F., et al. (2018). Heparin functionalization increases retention of TGF- $\beta 2$ and GDF5 on biphasic silk fibroin scaffolds for tendon/ligament-to-bone tissue engineering. Acta Biomaterialia, 72, 150-166.

[99] Bi, F., Chen, Y., Liu, J., Hu, W., Tian, K. (2021). Bone mesenchymal stem cells contribute to ligament regeneration and graft-bone healing after anterior cruciate ligament reconstruction with silk-collagen scaffold. Stem Cells International, 2021, 6697969.

[100] Sun, N., et al. (2019). Fabricated porous silk fibroin particles for $\mathrm{pH}$ psresponsive drug delivery and targeting of tumor cells. Journal of Materials Science, 54, 3319-3330.

[101] Gianak, O., Kyzas, G. Z., Samanidou, V. F., Deliyanni, E. A. (2019). A review for the synthesis of silk fibroin nanoparticles with different techniques and their ability to be used for drug delivery. Current Analytical Chemistry, 15(4), 339-348.

[102] Gianak, O., Pavlidou, E., Sarafidis, C., Karageorgiou, V., Deliyanni, E. (2018). Silk fibroin nanoparticles for drug delivery: Effect of bovine serum albumin and magnetic nanoparticles addition on drug encapsulation and release. Separations, 5(2), 25.

[103] Rahat, M. I., Sharma, S. K. (2020). Use of silk fibroinbased nanoparticles as a novel drug delivery system. European Journal of Molecular \& Clinical Medicine, 7(6), 999-1006.

[104] Mocchi, M., Bari, E. (2020). Silk-fibroin nano-drug delivery systems. Royal Society of Chemistry (London), 88-119.

[105] Yao, J., Wang, Y., Ma, W., Dong, W., Zhang, M., Sun, D. (2019). Dual-rrug-loaded silk fibroin/PLGA scaffolds for potential bone regeneration applications. Journal of Nanomaterials, 2019, 8050413.

[106] Hong, H., et al. (2021). Green electrospun silk fibroin nanofibers loaded with cationic ethosomes for transdermal drug delivery. Chemical Research in Chinese Universities, 37, 488-495.
[107] Niu, C., Li, X., Wang, Y., Liu, X., Shi, J., Wang, X. (2019). Design and performance of a poly(vinyl alcohol)/silk fibroin enzymatically crosslinked semi-interpenetrating hydrogel for a potential hydrophobic drug delivery. RSC Advances, 70(9), 41074-41082.

[108]Akrami-Hasan-Kohal, M., Eskandari, M., Solouk, A. (2021). Silk fibroin hydrogel/dexamethasone sodium phosphate loaded chitosan nanoparticles as a potential drug delivery system. Colloids and Surfaces B: Biointerfaces, 205, 111892.

[109] Marin, M. A., Mallepally, R. R., McHugh, M. A. (2014). Silk fibroin aerogels for drug delivery applications. The Journal of Supercritical Fluids, 91,84-89.

[110] Tomoda, B. T., Corazza, F. G., Beppu, M. M., Lopes, P. S. (2020). Silk fibroin membranes with self-assembled globular structures for controlled drug release. Journal of Applied Polymer Science, 137(16), 48763.

[111] Dorishetty, P., Dutta, N. K., Choudhury, N. R. (2020). Silk fibroins in multiscale dimensions for diverse applications. RSC Advances, 55(10), 33227-333247.

[112] Cheng, X., Long D., Chen, L., Jansen J. A., Leeuwenburgh, S. C. G., Yang, F. (2021). Electrophoretic deposition of silk fibroin coatings with pre-defined architecture to facilitate precise control over drug delivery. Bioactive Materials, 6(11), 4243-4254.

[113] Dong, Y., et al. (2015). Fabrication and characterization of silk fibroin-coated liposomes for ocular drug delivery. European Journal of Pharmaceutics and Biopharmaceutics, 91, 82-90.

[114] Shin, D., Hyun, J. (2021). Silk fibroin microneedles fabricated by digital light processing $3 D$ printing. Journal of Industrial and Engineering Chemistry, 95, 126-133.

[115] Wen, D. L., et al. (2021). Recent progress in silk fibroin-based flexible electronics. Microsystems \& Nanoengineering, 7, 35.

[116] Zhang, H., Zhao, J., Xing, T., Lu, S., Chen, G. (2019). Fabrication of silk fibroin/graphene film with high electrical conductivity and humidity sensitivity. Polymers, 11(11), 1774.

[117] Chao, M., et al. (2021). Breathable $\mathrm{Ti}_{3} \mathrm{C}_{2} \mathrm{~T}_{x}$ MXene/protein nanocomposites for ultrasensitive medical pressure sensor with degradability in solvents. ACS Nano, 15(6), 9746-9758.

[118] Yang, S., Liu, Q., Ren, J., Ling, S. (2021). Influence of hydrated protons on temperature and humidity responsiveness of silk fibroin hydrogel ionotronics. Giant, 4, 100044.

[119] He, F., et al. (2020). Stretchable, biocompatible, and multifunctional silk fibroin-based hydrogels toward wearable strain/pressure sensors and triboelectric nanogenerators. ACS Applied Materials \& Interfaces, 12(5), 6442-6450.

[120] Wang, Q., et al. (2020). Facile production of natural silk nanofibers for electronic device applications. Composites Science and Technology, 187, 107950.

[121] Zhou. J., et al. (2021). Humidity-sensitive, shapecontrollable, and transient zinc-ion batteries based on plasticizing gelatin-silk protein electrolytes. Materials Today Energy, 2021, 21, 100712.

[122] Zhou, Z., et al. (2017). The use of functionalized silk fibroin films as a platform for optical diffraction-based sensing applications. Advanced Materials, 29(15), 1605471. 
[123] Li, J., et al. (2021). Silk fibroin coated magnesium oxide nanospheres: A biocompatible and biodegradable tool for noninvasive bioimaging applications. Nanomaterials, 11, 695.

[124] Santos, M. V., et al. (2019). Femtosecond direct laser writing of silk fibroin optical waveguides. Journal of Materials Science: Materials in Electronics, 30,1684316848.

[125] Prajzler, V., Min, K., S., Nekvindova, P. (2018). The investigation of the waveguiding properties of silk fibroin from the visible to near-infrared spectrum. Materials, 11(1), 112.

[126] Garrido, I., et al. (2020). Photocatalytic performance of electrospun silk fibroin/ZnO mats to remove pesticide residues from water under natural sunlight. Catalysts, 10, 110.
[127] Zhou, J., Zhang, Y., Yang, Y. Q., Chen, Z. F., Jia, G. W., Zhang, L. (2019). Silk fibroin-graphene oxide functionalized melamine sponge for efficient oil absorption and oil/water separation. Applied Surface Science, 497, 143762.

[128] Wang, H., Liang, L., Cheng, X., Luo, Y., Sun, S. (2017). Facile fabrication of porous $\mathrm{ZnS}$ and $\mathrm{ZnO}$ films by coaxial electrospinning for highly efficient photodegradation of organic dyes. Photochemistry and Photobiology, 94(1), 17-26.

[129] Gao, X. C., Gou, J., Zhang, L., Duan S. S., Li, C. Z. (2018). A silk fibroin based green nano-filter for air filtration. RSC Advances, 8, 8181.

[130] Min, K., Kim, S., Kim S. (2018). Silk protein nanofibers for highly efficient, eco-friendly, optically translucent, and multifunctional air filters. Scientific Reports, 8, 9598. 